\title{
Multi-instrument in-situ damage monitoring in quasi-isotropic CFRP laminates under tension
}

Fatih E.Oz ${ }^{a}$ NuriErsoy ${ }^{a}$ MahoorMehdikhani ${ }^{b}$ Stepan V.Lomov ${ }^{b}$

a Department of Mechanical Engineering, Bogazici University, Bebek 34342, Istanbul, Turkey

${ }^{\mathrm{b}} \mathrm{KU}$ Leuven, Department of Materials Engineering, Kasteelpark Arenberg 44, 3001 Leuven, Belgium

\begin{abstract}
Digital Image Correlation monitoring of the surface strains, microscopic in-situ observations of the micro-damage on the specimen edge and Acoustic Emission (AE) are utilized simultaneously during tension tests of quasi-isotropic carbon fibre reinforced polymer composites. It is found that the cluster analysis for characteristic parameters of $\mathrm{AE}$ events (the main being the signal amplitude and frequency) does not unambiguously identify the type of damage which causes the event. With optical instruments, it is observed that the signatures of $A E$ events depend on the position of the ply where damage happens and on the ply orientation $\left(90^{\circ} \mathrm{vs} 45^{\circ}\right)$. Robust evidences for the variations in $A E$ characteristics of damage modes in different lay-ups are presented. AE events, originated from surface cracks, have high amplitude and low frequency, whereas AE events, originated from transverse cracks in the inner plies, have low amplitude and high frequency characteristics. Any conclusion for fibre breaks are not reached in this study. Therefore, measurements in this study rather point out that the AE events, which could be interpreted as fibre breaks because of their high frequency characteristics, as optical observations prove, correspond to other damage types in quasiisotropic laminates.
\end{abstract}

Keywords: Damage mechanics, Acoustic emission, Digital Image Correlation (DIC), Carbon fibre, Polymer-matrix composites (PMC)

\section{Introduction}

Damage initiation and progression in composite materials involves complex mechanisms. Understanding these mechanisms is difficult but even detecting damage in composite materials is not an easy task. Tension stress-strain response of carbon fibre reinforced composite materials is almost linear and it is difficult to detect first ply failure and damage progression solely using this curve. Additional tools are required to determine the first damage load level and the damage accumulation. Acoustic Emission (AE) is assumed to be a promising technique for this task. Damage thresholds can be determined easily by using the cumulative number of $A E$ events or AE energy accumulation [1], [2], [3], [4], [5], [6]. However, damage mode identification with AE is not straightforward. It is done by classifying single $A E$ parameters or by evaluating multiple $A E$ parameters with clustering algorithms. Most preferred AE parameters for damage mode classifications are the amplitude [7], [8], [9], [10], [11], [12], [13], [14] and the frequency contents [13], [14], [15], [16], [17], [18], [19], [20]. They are also seen to be very selective for clustering [19], [20], [21], [22], [23], [24], [25], [26], [27], [28], [29]. Table 1 summarizes damage mode classifications that can be found in literature with respect to amplitude and peak frequency. Table 1 presents certain inconsistencies, which is not surprising as each study involves different fibre, matrix and laminate types whose wave propagation properties are different and cause variations in quantitative AE results. 
Table 1. AE signals amplitude and frequency ranges, attributed to different damage modes in literature.

Amplitude, dB

\begin{tabular}{|l|l|l|l|l|l|}
\hline Reference & $\begin{array}{l}\text { Matrix } \\
\text { cracking }\end{array}$ & Debonding & Delamination & Fibre pull-out & $\begin{array}{l}\text { Fibres } \\
\text { Breakage }\end{array}$ \\
\hline$[7]$ & $40-55$ & $60-65$ & $60-65$ & $65-85$ & $85-95$ \\
\hline$[8]$ & $45-55$ & - & $55-65$ & $65-85$ & - \\
\hline$[9]$ & $40-60$ & $60-80$ & $80-100$ & - & $80-100$ \\
\hline$[10]$ & $40-55$ & $55-75$ & $55-75$ & - & $80-100$ \\
\hline$[23]$ & $40-80$ & $50-80$ & $70-100$ & $70-100$ & $70-100$ \\
\hline$[11]$ & $60-77$ & & $77-90$ & $>90$ & \\
\hline$[12]$ & $40-60$ & $50-70$ & $60-80$ & $80-100$ & $80-100$ \\
\hline$[13]$ & $75-85$ & - & $60-80$ & & $85-105$ \\
\hline$[26]$ & $35-55$ & $55-100$ & $35-80$ & - & $35-80$ \\
\hline$[27]$ & $<55$ & - & $>55$ & & $35-100$ \\
\hline$[28]$ & $\leq 70$ & & & & $30-90$ \\
\hline
\end{tabular}

Peak Frequency, kHz

\begin{tabular}{|l|l|l|l|l|l|}
\hline Reference & $\begin{array}{l}\text { Matrix } \\
\text { cracking }\end{array}$ & Debonding & Delamination & Fibre pull-out & $\begin{array}{l}\text { Fibres } \\
\text { Breakage }\end{array}$ \\
\hline$[13]$ & $170-250$ & - & $100-130$ & & $350-450$ \\
\hline$[14]$ & $140-250$ & $250-350$ & & & $350-450$ \\
\hline$[15]$ & $50-180$ & $220-300$ & $225-300$ & $180-220$ & $>300$ \\
\hline$[16]$ & $90-110$ & - & & $200-300$ & $>420$ \\
\hline$[17]$ & $200-600$ & $200-350$ & $100-500$ & $700-1100$ & $>1500$ \\
\hline$[18]$ & $\approx 140$ & $\approx 300$ & & - & $\approx 405$ \\
\hline$[19]$ & $<50$ & $200-300$ & $50-150$ & $500-600$ & $400-500$ \\
\hline$[20]$ & $80-250$ & $250-375$ & - & - & $375-480$ \\
\hline$[26]$ & $50-80$ & $50-150$ & $150-500$ & - & $150-500$ \\
\hline$[27]$ & $<180$ & - & $>180$ & & $>180$ \\
\hline$[28]$ & $<300$ & & & & $\geq 300$ \\
\hline
\end{tabular}

The general approach to the AE-based damage mode identification, used in the open literature, is as follows. Simple tests are done to obtain AE characteristics corresponding to specific damage modes. For example $A E$ characteristics of matrix cracks are determined with tension tests of neat resin material or of unidirectional (UD) [90] $n$ laminates. For fibre breakage, UD [0]n composites or fibre bundles are tested in tension. [0]n and [90]n composite specimens are also used for fibre/matrix debonding. Fracture tests are done for AE characteristics of delamination. Finally, AE results of more complex laminates are evaluated based on the AE characteristics obtained in these simple tests, with confirmation based on post-mortem damage observations [8], [10], [12], [16], [18], [19], [20], [22], [25], [30], [31]. Then, AE events with these characteristics are matched to predetermined damage modes regardless of the laminate lay-up. Most of the results presented in the literature were interpretations, not direct correlations.

Misinterpretations are possible due to the through thickness distance of the damage source to the AE sensors. The effect of through thickness distance of a damage in the material on the frequency 
values was previously shown in large aluminium plates by Hamstad et al. [32]. It was found that the peak frequency values of same damage mode was decreasing as the source was approaching to the surface of the material and the wavelet transformation (WT) of the signals was changing to flexural mode (AO) from extensional mode (SO). Scholey et al. [33] examined this situation in large QI CFRP plates. Large plates were containing a cut in the middle of the specimen to stimulate two specific damage modes in the order of matrix cracking and delamination. It was found that matrix cracking events were dominated by the SO, whereas delamination was dominated by the A0 guided wave modes and their amplitudes were varying with respect to the propagation angle and through thickness distance to the sensors. These two studies consider large plates to minimize distortions in the $A E$ events due to the reflections from the edges [32], [33]. Because the elastic energy waves are reflected from the plate edges into the specimens and they interfere with the waveform of the real AE event of a damage which put more weight on low frequency contributions [32], [33]. However, WT and the FFT should be studied in coupon specimens in accordance with the recommended dimensions of the test standards. Sause et al. [34], [35] simulated guided AE waves of same damage modes in $3 \mathrm{~mm}$ thick laminates, having different stacking sequences. It was found that stacking sequence and the through thickness distance of the damage causes substantial changes in the guided wave of the $A E$ event and the frequency content. Moreover, AE results registered during the tension tests of six different cross-ply (XP) laminates showed that different configurations caused noticeable changes in AE cluster boundaries for each failure mechanisms [35], [36]. It was concluded that the number of matrix cracking events (low weighted frequency events) and the number of fibre breaks (high weighted frequency events) increase with the number of $90^{\circ}$ and $0^{\circ}$ plies in different XP laminates [35], [36].

A typical example of misinterpretation is the conventional belief that matrix cracks and fibre breakage correspond to low and high peak frequency values respectively as in Table 1. However, Baker et al. [37] and Maillet et al. [38] showed that high peak frequency values were recorded in XP laminates in spite of the fact that the only observed damage mode was transverse cracks in $90^{\circ}$ plies. The damage was directly observed during the test by imaging the edges of the specimens [37]. This work shows the drawback of using the $A E$ technique solely for damage characterisation and suggests that application of additional techniques simultaneously with $A E$, such as optical monitoring is required for efficient damage mode identification.

Such an observation is relatively easy when the laminates are transparent (see, for example, [27], where plain weave glass fibre reinforced composites were tested). However, it is not easy for nontransparent materials, as Carbon Fibre Reinforced Polymer (CFRP) composites. Digital Image Correlation (DIC) is a popular method used for strain measurement and damage detection on material surface [2], [39], [40], [41], [42], [43], [44], [45], [46], [47], [48], [49]. It can provide a direct correlation of surface cracks with $A E$ recordings but not for micro damage in the inner plies. There are few cases where DIC is used to detect the progression of internal damage. For example, Schorer et al. [50] tested UD CFRP specimens containing artificially introduced defects in the inner plies. Fibre breaks, delamination and inter-fibre damage modes were introduced in UD laminates before the tests. It was found that 3D DIC technique can successfully identify the damage initiation and the progression from these artificially induced defects [50]. Similarly, Suarez et al. [51] used 3D DIC and $A E$ registration techniques during tension tests of UD CFRP plates containing Fibre-optic Bragg Grating (FBG) sensors which can stimulate damage initiation under tension loading. It was seen that 3D DIC technique can detect damage around the FBG sensors and there is a good correlation between the DIC results and AE results in terms of detecting position of the damage. So, damage initiations from artificially introduced cuts (as in [50]) or inter-fibre elements (as in [51]) in UD laminates can be detected with 3D DIC technique. What is the ability of DIC technique for detecting 
damage in the inner plies of uniform laminates? Sause [35] found that, DIC allows capturing of transverse cracks in $90^{\circ}$ plies of a [0/90] s laminate, which appear as strain concentrations on surface $0^{\circ}$ plies. It was concluded that detectability of damage with 3D DIC technique was limited to surface plies for uniform laminates. Detection of delaminations in the inner intersections was not addressed [35]. Mehdikhani et al. [52] performed an in-situ multi-scale DIC analysis to characterize transverse cracking in CFRPs. They presented a semi-automatic technique to detect matrix cracks in the DIC data of the surface and edge of the laminate and to process the crack density evolution as function of the applied strain.

Carvelli et al. [29] used DIC for the purpose of strain measurement only and an additional optical method to correlate damage modes with AE clusters for cross-ply (XP) woven carbon fibre reinforced thermoplastic. In-situ edge observation was done by a Charge-Couple Device (CCD) camera with a high magnification lens to follow micro damage propagation in the inner plies since DIC measurement on the front surface is unable to detect all transverse matrix cracks in the inner plies, away from the surface. Recently, authors of the current paper found that DIC and in-situ edge microscopy with a CCD camera, having high magnification lens, can successfully identify macro delaminations at $+45 / 90$ interfaces and transverse cracks in the inner $90^{\circ}$ and $+45^{\circ}$ plies of [-452/02/+452/902]s laminates [53]. More importantly, it was found that high frequency AE events did not necessarily correspond to fibre breaks, but they had high consistency with the propagation of transverse matrix cracks in the inner $+45^{\circ}$ and $90^{\circ}$ plies [53].

In this study, DIC monitoring of the surface strains, microscopic in-situ observations of the microdamage on the specimen edge and $A E$ registration are utilized simultaneously during tension tests of four different lay-ups of Quasi-Isotropic (QI) CFRP composites. An unsupervised k-means++ clustering algorithm, previously applied in [28], [29], [53] to CFRP woven and prepreg composites, is used for AE results. Well-separated and dense clusters are recognised but it is found that those clusters cannot be unambiguously used to identify the type of the damage which caused the event. In-situ edge observation enables to detect transverse cracks in $90^{\circ}$ and $\pm 45^{\circ}$ plies with micro delaminations at their interface. It is seen that, $A E$ characteristics of transverse cracks are highly dependent on through thickness positions of $90^{\circ}$ and $\pm 45^{\circ}$ plies. Damage in the inner plies are linked with high frequency events but not fibre breaks and micro delaminations are always registered with low amplitude-low frequency events in any laminate type as presented for one QI laminate type in authors' previous study [53]. The present study builds on the preliminary findings reported in authors' previous study [53] and examines the variations in AE characteristics with lay-up sequence. It demonstrates the effect of lay-up on the sequence of damage modes and on the AE characteristics corresponding to these damage modes, and emphasizes the necessity to avoid broad generalizations about the correspondence of the AE characteristics to damage modes and evaluate each laminate type individually. Furthermore, the doubt expressed about the correlation of high frequency events with fibre breaks in [37], [38] is justified with more evidence. Findings of this study provide a new point of view to interpret the $A E$ characteristics of damage modes in composite materials.

\section{Material and experimental methodology}

\subsection{Material}

The QI laminates, used in this study, are produced using Hexcel's UD AS4/8552 prepregs. The fibre volume fraction and nominal thickness of the prepregs are $57.4 \%$ and $0.184 \mathrm{~mm}$ respectively. Reported results of this study are a part of a large experimental programme on AE investigation of damage in QI CFRP laminates with different geometries, lay-up and ply scaling. Only the results of four specimens with $3 \mathrm{~mm}$ thickness, $15 \mathrm{~mm}$ width and $175 \mathrm{~mm}$ length are reported here: a) 
[-452/02/+452/902]s, b) $[902 /-452 / 02 /+452] s$, c) $[02 /+452 / 902 /-452] s$, and d)

[+452/902/-452/02]s. Large QI plates are manufactured according to Manufacturer's Recommended Cure Cycle [54] inside an autoclave at Bogazici University. Specimens are cut from the large plate with a water-cooled diamond saw. QI glass fibre reinforced composites with $1.5 \mathrm{~mm}$ thickness and $50 \mathrm{~mm}$ length are used for end tabs. Their gauge section ends are tapered to $20^{\circ}-30^{\circ}$ to minimize stress concentrations and prevent failure from grip sections. One edge of several specimens was polished for microscopic in-situ edge observation.

\subsection{Tension tests}

Tension tests are performed with electro-mechanical Instron 4505 universal test machine according to ASTM D3039 standard [55] with a test rate of $1 \mathrm{~mm} / \mathrm{min}$. Extensometry and local strain measurement is done optically. Micro damage development on the specimen edges is observed with the second camera. The experimental setup is shown in Fig. 1, details of each instrumentation technique are given in further subsections.

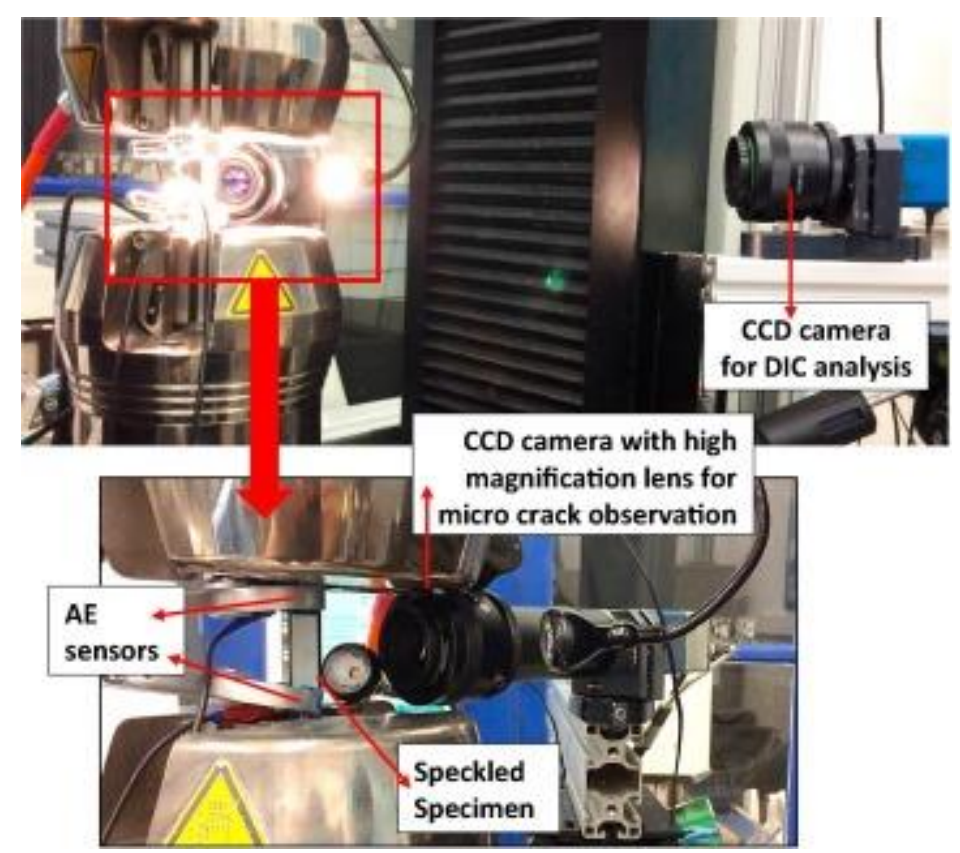

Fig. 1. Experimental setup.

\subsection{Acoustic emission}

$A E$ is considered as a robust method for online damage registration in composite materials. An $A E$ signal dissipates as an ultrasonic wave resulting from the sudden release of the strain energy when damage happens. It propagates through the medium and detected with AE sensors placed on the medium.

Vallen AE system with two broadband Digital Wave B-1025 AE sensors, having $10 \mathrm{~mm}$ diameter, is used in this study. Frequency range of these sensors is $25-1600 \mathrm{kHz}$. Two filters are applied for AE registration. First one is for amplitude threshold level. $A E$ events having amplitude lower than $40 \mathrm{~dB}$ are filtered out. Second one is a location filter. AE sensors are placed $50 \mathrm{~mm}$ away from each other and only the events between and at least $5 \mathrm{~mm}$ away from each sensor are recorded. In order to 
calibrate the real location of damage with $A E$ detection, pencil lead break test is done before the tests. Mechanical pencil lead tip with dimension of $0.5 \mathrm{~mm}$ diameter and $3 \mathrm{~mm}$ length is broken at different locations on specimen surface. It is seen that pencil lead breaks have at least $80 \mathrm{db}$ amplitude but there is about 1-2 $\mathrm{mm}$ discrepancy between the real location of the lead break and the corresponding AE event position.

In order to find similarities between the recorded AE signals and classify them properly to correlate with the damage modes, clustering algorithms are used. Sause et al. [24] developed a very efficient algorithm with semi-automated pattern recognition methodology, considering four evaluation indices at the same time and doing a sort of averaging when the optimal number of clusters is not the same for all cases [24], [25]. We used a simpler procedure [26], [27], [28], [29], as it turned out to be sufficient for effective cluster segregation in this particular work. Details of this clustering algorithm can be found in [28] and a brief summary is given here. Nine features are identified for each AE event: Amplitude (A), Duration (D), Rise Time (R), Energy (E), logarithmic value of Energy $(\log E)$, peak frequency (FMAX) and frequency centroid of gravity (FCOG), Rise Amplitude (RA) and Weighted Peak Frequency (WF). RA shows the reciprocal of gradient in AE signal waveform, its value is calculated by dividing rise time to amplitude. WF was first introduced by Sause et al. [24] to improve the representative characteristics of frequency associated with an acoustic emission signal combining the discriminative efficiency of the FMAX with the information on the average frequency content of the signal expressed by the FCOG. Its value is geometric mean of FMAX and FCOG.

First step in this clustering algorithm is choosing the relevant features that are statistically representative. Laplacian score of the AE parameters are attained with a value between 0 and 1 . A higher score means a more selective feature for clustering. Correlation coefficient is another parameter, evaluated with Laplacian score to choose relevant features. It shows the dependency of features on each other. If $A E$ features have high Laplacian score and low dependency on other features, then they are selected for the clusters formed by Principal Component Analysis (PCA) and k-means++ algorithm. PCA is an orthogonal linear transformation that transforms multidimensional AE data into lower dimension set with a new coordinate system. The k-means++ is a modified way of choosing centres for the k-means algorithm [28]. It is based on an iterative algorithm where data samples are distributed to the closest centroids. The number of clusters is chosen with respect to two evaluation indices. First one is Silhouette Coefficient which has value between 0 and 1 . Higher Silhouette Coefficient score means dense and well-separated clusters. Second one is Davies-Bouldin index which is based on a ratio within-cluster and between-clusters distances and it relates to the cluster centroids. Combination of higher Silhouette coefficient and lower Davies-Bouldin index means better cluster quality.

In all the cases studied the clustering algorithm leads to the same configuration of three or four clusters, with the main parameters being the signal amplitude and one of the frequency-related parameters. Keeping in mind that the clusters are segregated in a full set of the AE event parameters, the clusters can be described in four "quadrants" in "amplitude - frequency" plane as "low/high amplitude - low/high frequency" clusters. This is explained in detail in Section 3.

\subsection{Digital Image Correlation}

The main purpose of using Digital Image Correlation (DIC) is measuring local strains during tests. LIMESS DIC system is used for this purpose. Speckle pattern is sprayed on one surface of the laminates and used for DIC calculations. Two photos are captured per second by a CCD camera during testing. Acquisition is done with VIC snap software. Resolution of the photos is $1392 \times 1040$ pixel2. VIC 2D software is used for DIC calculations. $27 \times 14 \mathrm{~mm} 2$ region of the 
specimens is selected as Area of Interest (Aol) from a reference image taken at the beginning of the tests. Displacement of the speckles from the Aol is used to calculate deformation during testing by DIC. Subset and step sizes are set to 21 and 4 respectively. In this study, DIC analyses are performed with normalized square differences criterion, optimized 4-tap interpolation and Gaussian subset weights. Finally, Lagrangian strains are computed from the displacements of the speckles. At the end, deformation maps are investigated to identify surface cracks. Moreover, macro damage zones (large delaminations) within the laminates are determined from 2D full-field deformation maps for some laminate types.

\subsection{Edge observation}

Surface DIC is not able capturing micro cracks in inner plies. For this aim, a third damage detection technique is used. Free edge of the specimen is observed directly during tension tests. A CCD camera with high magnification lens is used to take photos simultaneously with DIC (2 photos per second). This technique enables to focus to a $5 \times 3.2 \mathrm{~mm} 2$ frame of one edge of the specimens. The resolution of the image is $1392 \times 1040$ pixel2. This allows capturing matrix cracks, fibre/matrix debonding and delaminations in the inner plies. Fig. 2 shows a typical edge image with identification of the crack types.

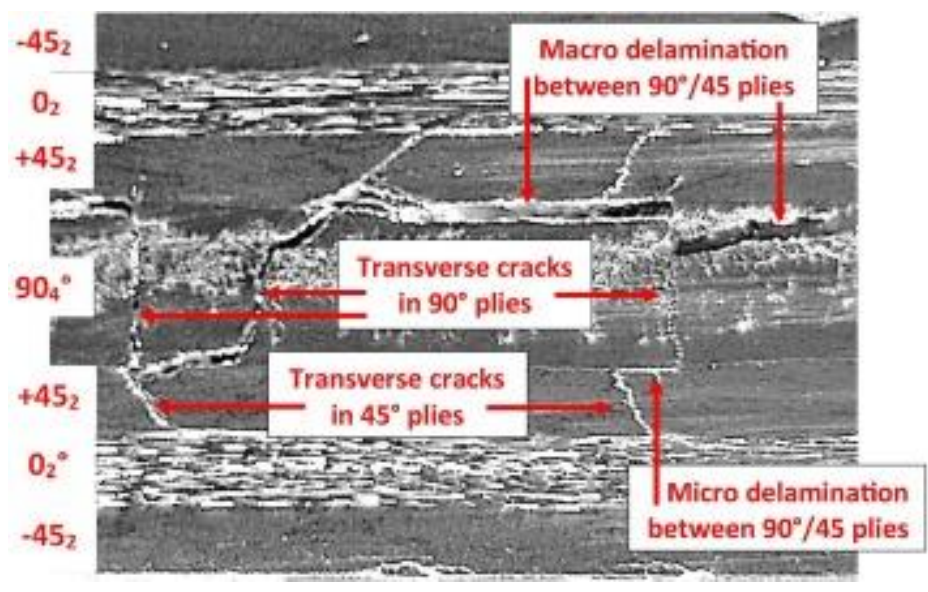

Fig. 2. Typical edge image from $[-452 / 02 /+452 / 902] s$ laminate with certain damage modes.

\section{Test results}

Five tension tests are performed for each laminate type with AE registration and DIC measurements. Direct edge observation is utilized during two of these tests. Fig. 3 presents test results for all layups, combining in one graph stress-strain curve and parameters of the AE events: Amplitude with cumulative AE energy and weighted frequency. Different colours of the symbols and lines represent a different test. Reason for choosing weighted frequency is explained in further sections. The specimens are not tested up to the final failure to prevent possible damage to the AE sensors, hence the maximum stress levels in Fig. 3 do not correspond to the ultimate strengths of the specimens, but rather the stress levels that particular tests are stopped. Fig. 3 shows that the measurements for different specimens with the same layup present small scatter: stress-strain curves, cumulative $A E$ curves and distribution of the AE events are consistent. Stress-strain curves for the different layups are the same within the experimental scatter, which is of no surprise. AE patterns, both expressed as cumulative energy curves and as distribution of the amplitude and frequency of the events change considerable as lay-up orientation changes: compare Fig. 3a to d. 


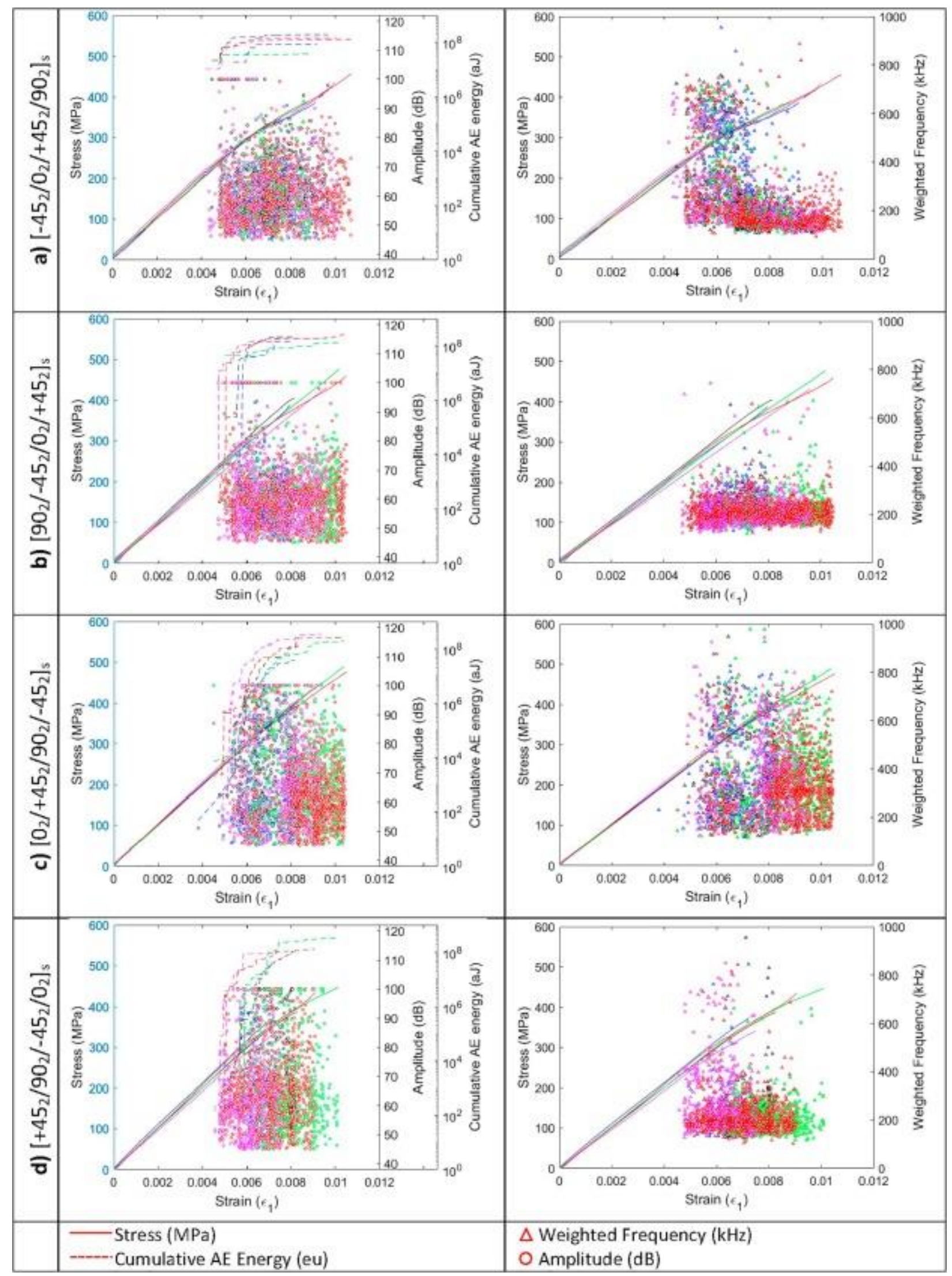

Fig. 3. A summary of the stress-strain curves and $A E$ registration for the tested laminates a) $[-452 / 02 /+452 / 902] s$, b) $[902 /-452 / 02 /+452] s$, c) $[02 /+452 / 902 /-452] s$ d) $[+452 / 902 /-452 / 02] s$. Markers and lines of different colours correspond to different individual tests. 
When $90^{\circ}$ plies are mid-plies or close to mid-section, high frequency events are registered massively, as shown in Figs. 3.a and c. Conversely, when $90^{\circ}$ plies are on or close to surface of the laminate, most of the AE events have low weighted frequency values between 100 and $400 \mathrm{kHz}$ as shown in Fig. 3.b and d. Thus, lay-up orientation causes considerable changes in AE results. Validity of the assumption that states the correlation between fibre breaks and high frequency events and low frequency with matrix cracks becomes contentious in the light of our measurements.

High frequency events are registered from the very beginning of the AE activity in $[-452 / 02 /+452 / 902] s$ and $[02 /+452 / 902 /-452] s$ laminates. They have more or less constant number with high amplitude and energy. These features are difficult to associate with fibre breakage. In addition to this, a question can be asked: "Does the order of damage evolution change from one laminate to another and cause a different configuration of the AE event clusters?" Baker et al. and Maillet et al. [37], [38] put forward their doubts about this by presenting optical damage observations for cross-ply [90/0]6s and [0/90]6s laminates. Even though, only transverse cracks were observed in $90^{\circ}$ plies during tension tests of both laminates, high peak frequency events were recorded for [0/90]6s whereas only low frequency events were recorded for [90/0]6s[37], [38].

The AE patterns in QI laminates, presented in Fig. 3, also suggest that indeed the conventional identification of the high frequency events as fibre breakage is questionable and that the layup of a laminate can qualitatively modify the AE pattern. The subsequent sections put this general observation of the AE events in conjunction with DIC and the edge optical damage observations. Only the test results where all damage identification techniques are utilized are presented in subsequent sections.

\section{1. $[-452 / 02 /+452 / 902] s$ laminate}

This section details the findings in authors' previous paper [53]. First, we use example of this lay-up to confirm that the weighted frequency (WF) is the most selective frequency parameter. AE cluster groups with respect to different frequency parameters vs. amplitude for this laminate are shown in Fig. 4. It is seen that the clusters are well-separated with respect to weighted frequency vs.

amplitude and shows evident mixture of clusters for Peak Frequency and Frequency Centroid. Table 2 shows the summary of cluster boundaries with respect to amplitude and weighted frequency. 


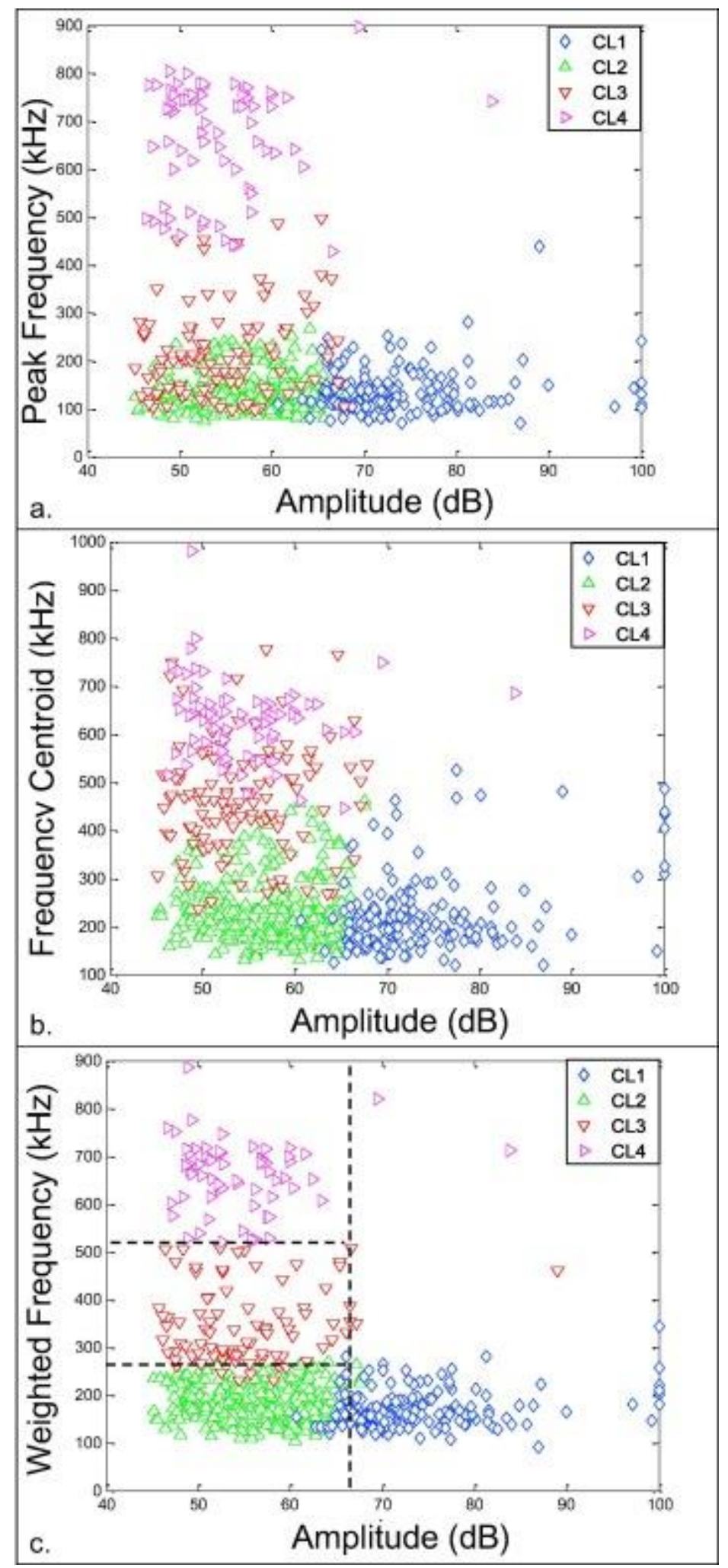

Fig. 4. Cluster groups for of $[-452 / 02 /+452 / 902] s$ laminate. 
Table 2. Summary of cluster groups of AE results for $[-452 / 02 /+452 / 902] s$ laminate.

Summary of cluster boundaries

$\begin{array}{llll} & & \mathrm{A}(\mathrm{dB}) & \mathrm{WF}[\mathrm{kHz}] \\ \mathrm{CL} 1 & \diamond & \geq 66 & \leq 260 \\ \mathrm{CL} 2 & \Delta & <66 & \leq 260 \\ \mathrm{CL} 3 & \nabla & <66 & 260<\mathrm{WF} \leq 480 \\ \mathrm{CL} 4 & \triangleright & <66 & >480\end{array}$

Fig. 5.a shows the accumulation of clusters with respect to the two most selective parameters for the gauge region between the AE sensors. High frequency - low amplitude events (CL3-CL4) are mostly recorded during early $A E$ registration whereas high amplitude - low frequency features (CL1$\mathrm{CL2}$ ) are seen after around 0.0067 strain. Fig. 5.b presents the same for the edge observation region only. It shows that the events pattern for this region is representative for the whole specimen. 


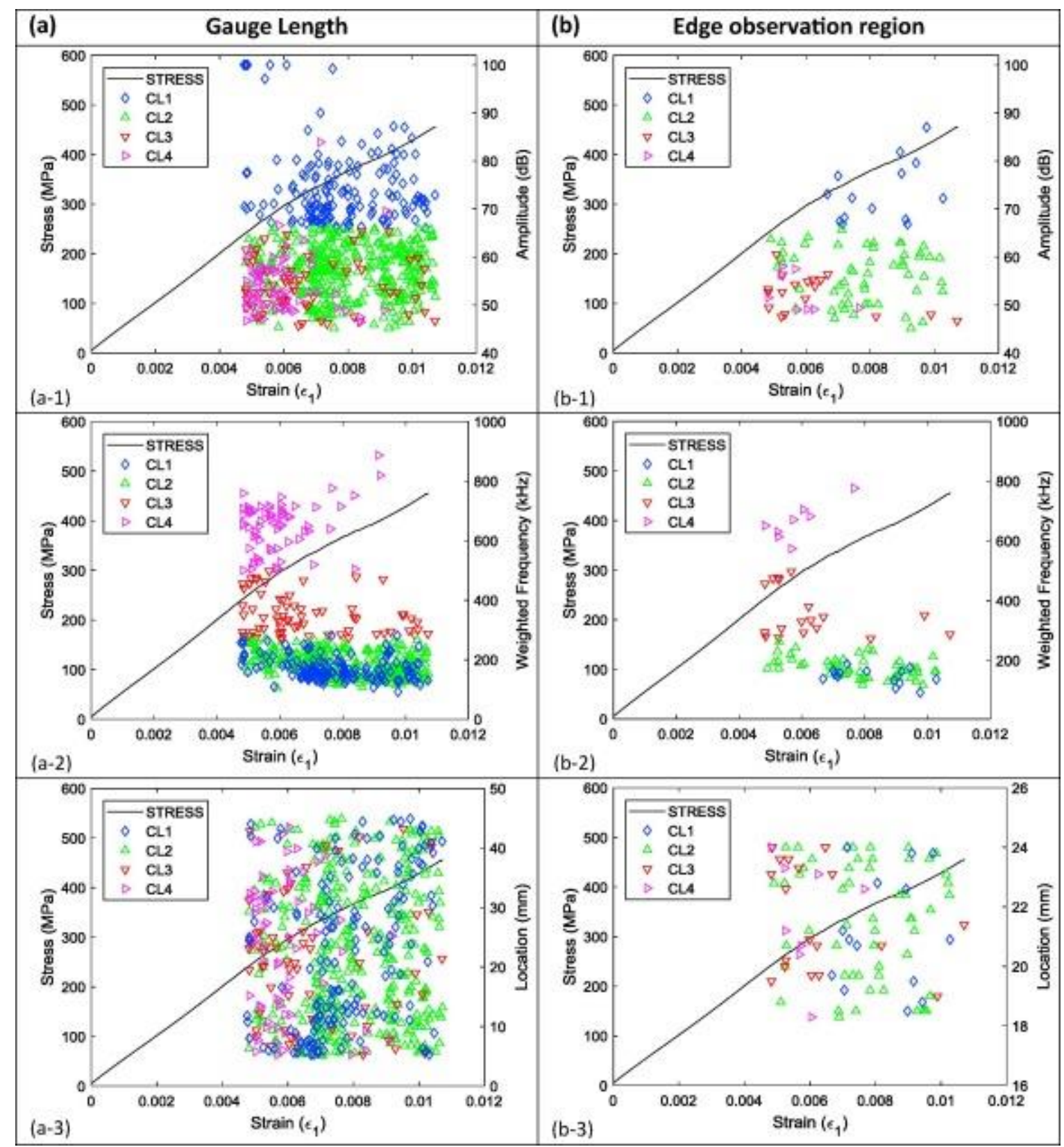

Fig. 5. Accumulation of $A E$ clusters throughout a test in [-452/02/+452/902]s laminate: (a) full gauge length; (b) edge observation region only; (1) events amplitude; (2) events weighted frequency; (3) events location.

Damage evolution throughout the test can be seen in Fig. 6 . The very left column in Fig. 6 shows strain levels in test direction. These strains are the average $\varepsilon 1$ values (direction 1 designates the loading direction, direction 2 is the transverse direction), calculated from the Aol used for the strain mapping. "Edge observation region" is marked on Fig. 6 . The closest distance of this region to the AE sensor with zero location is $18 \mathrm{~mm}$; the region covers the location range $18-23 \mathrm{~mm}$. Due to discrepancy between AE detection and real location, 18-24 $\mathrm{mm}$ region is taken into consideration. Snapshots of micro damage evolution within this $5 \mathrm{~mm}$ region can be seen on second column of the Fig. 6. Next two columns present full field $\varepsilon 1$ and $\varepsilon 2$ strain maps respectively. 


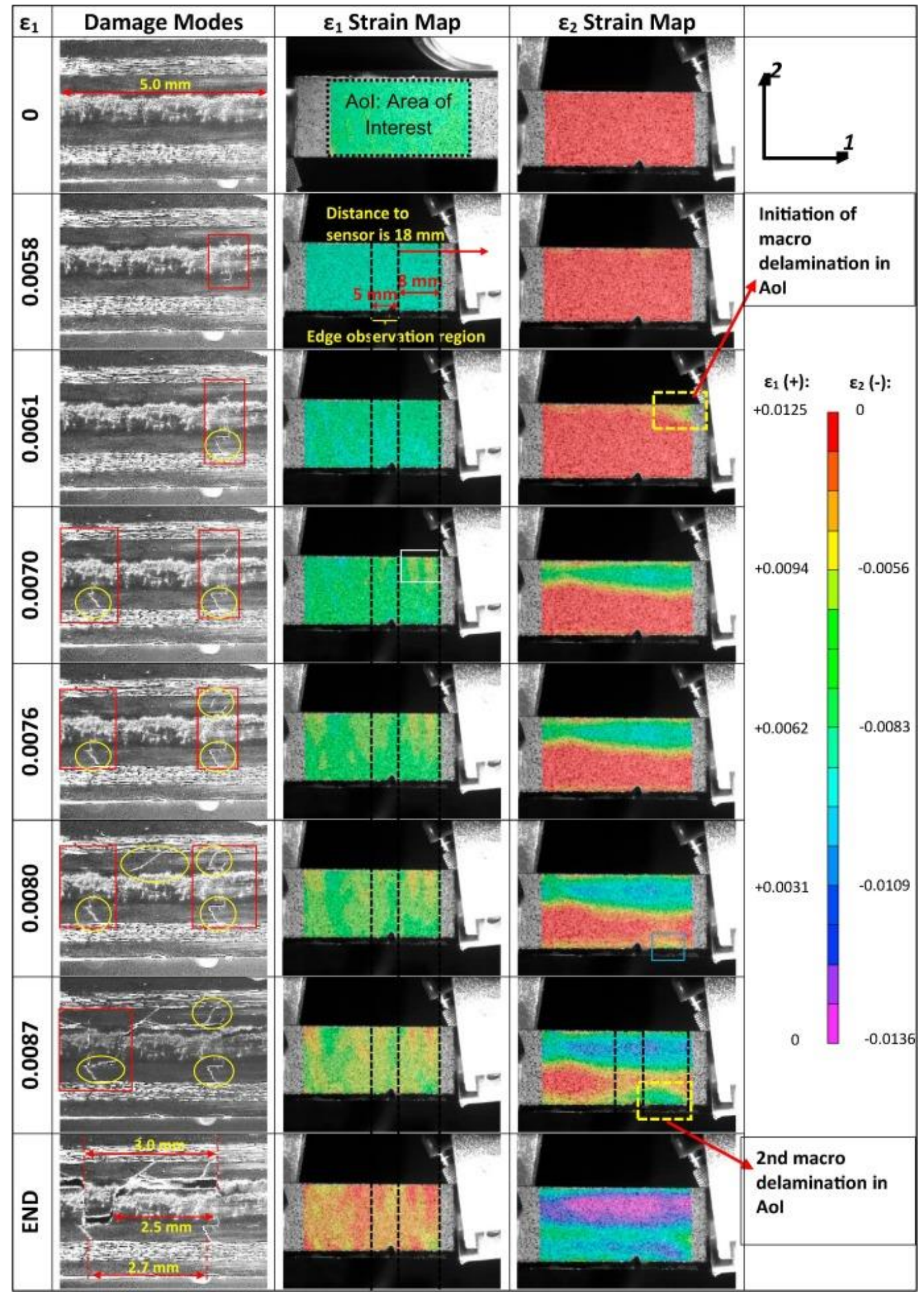

Fig. 6. Damage accumulation in $[-452 / 02 /+452 / 902] s$. 
First micro damage mode is a transverse matrix crack in mid- $-90^{\circ}$ plies; it is seen at 0.0058 strain in Fig. 6 . The moment of this image is about 0.0010 strain later than the damage threshold, suggested by the start of $A E$ activity (Fig. 5.b). Then the damage propagates to adjacent lower $45^{\circ}$ plies at 0.0060 strain with micro delamination at $90^{\circ} / 45^{\circ}$ interface. A similar damage, consisting of transverse matrix cracks in mid $90^{\circ}$ plies, off-axis cracks in adjacent lower $45^{\circ}$ plies and micro delamination between them are seen at around $3 \mathrm{~mm}$ away from the first damage at 0.0070 strain. Then, the first transverse crack propagates to upper $45^{\circ}$ plies at 0.0076 strain. Similar damage propagation occurs with the second transverse cracks at 0.0080 strain. Afterwards, $90^{\circ}$ plies and adjacent $45^{\circ}$ plies separate from each other at 0.0087 strain, as seen in Fig. 6 . Large separation of $90^{\circ}$ layers from $45^{\circ}$ layers is called "macro delamination" in this study. This test is stopped at 0.0110 strain and $455 \mathrm{MPa}$ stress level.

As shown in Fig. 5.(a-3), the origins of the AE events, belonging to different clusters, are quite evenly distributed over the length of the specimen. This suggests that the sequence of the damage events seen in the $5 \mathrm{~mm}$ length of the edge observation region also happens in other parts of the specimen. Hence we can discuss the damage evolution using overall $A E$ registration and DIC images of the full Aol.

Fig. 5 shows that the number of events in high frequency clusters, (CL3-CL4) are more than in low frequency clusters (CL1-CL2) until around 0.0067 strain. Then number of events in the low frequency - high amplitude cluster (CL1) increases. At the same time, there is very high contraction (green-blue zone, corresponding to the high absolute values of $\varepsilon 2$ ) on one side of the specimen, seen from the $\mathrm{DIC}$ strain map of $\varepsilon 2$ at 0.0070 strain in Fig. 6 . This contraction is due to the delamination between $90^{\circ}$ and $45^{\circ}$ plies which initiates at 0.0061 strain and completely propagates through the gauge length at around 0.0070 strain. Before delamination, the surface plies could not develop Poisson contraction because they are constrained by the $90^{\circ}$ ply. After delamination the constraint is removed, and $\varepsilon 2$ increases in the delamination area. Delamination of $90^{\circ}$ and $45^{\circ}$ layers from each other in the edge observation region occurs at 0.0087 strain level as shown in Fig. 6 . It can be assumed that the increase in the number of CL1 events is due to this delamination between $90^{\circ}$ and $45^{\circ}$ plies. Similar damage mode initiates from the polished side of the specimen, marked within a box inside $\varepsilon 2$ plot at 0.0080 strain level.

Correlation between damage modes and AE clusters can be done using the in-situ optical observations. Fig. 6 shows that only micro cracks occur in the inner plies before 0.0070 strain, and most of the recorded signals before 0.0070 strain are high frequency - low amplitude clusters (CL3$\mathrm{CL} 4$ ) as seen in Fig. 5. Macro delamination initiates near one side of the specimen at 0.0061 strain and propagates through the gauge length at 0.0070 strain as shown in Fig. 6 , whereas, Fig. 5.a shows that the number of events in the high amplitude-low frequency cluster, CL1, increases considerably in gauge length during the same strain interval. Fig. 5.(a-3) shows that high number of CL1 starts to be recorded from 0.0061 strain at 8-9 mm away from the sensor, then it propagates to $10-12 \mathrm{~mm}$ away at around 0.0067 strain level, afterwards it is distributed to further regions. CL1 appears after around 0.0065 strain in the edge observation region as shown in Fig. 5.b. Hence a correlation between the clusters and observed damage modes can be done as follows:

- CL3-CL4 (high frequency - low amplitude) represent transverse matrix cracks in $90^{\circ}$ and $45^{\circ}$ plies.

- CL1 (low frequency - high amplitude) represent macro delaminations - separation of $90^{\circ}$ and $45^{\circ}$ plies.

- CL2 (low amplitude - low frequency) represents micro delaminations already present from first damage initiation stress level until the end of the test. 
Fibre breaks are not present in this classification. We are able to make links between all the clusters with certain damage types. Evidently, it is found out that high frequency events represent matrix cracks in the inner $90^{\circ}$ and $+45^{\circ}$ plies. Doubts in [37], [38] are supported: high frequency events do not necessarily represent fibre breaks. Where are the fibre breaks? One possibility is that they cause low amplitude AE signals which are filtered away by the threshold of $40 \mathrm{~dB}$. Lowering this threshold is not possible because of the level of the noise in the used sensors and the acquisition system.

Additional evidence supporting the proposed correlation between the AE events clusters and the damage modes is given by the analysis of the cracks spacing. Fig. 7 presents distribution of location of the $A E$ events in different clusters for a region of 10-25 $\mathrm{mm}$ away from one $A E$ sensor; the region of the edge microscopic observation is marked on these graphs. Note that the error in the event location is about $1 \mathrm{~mm}$. 


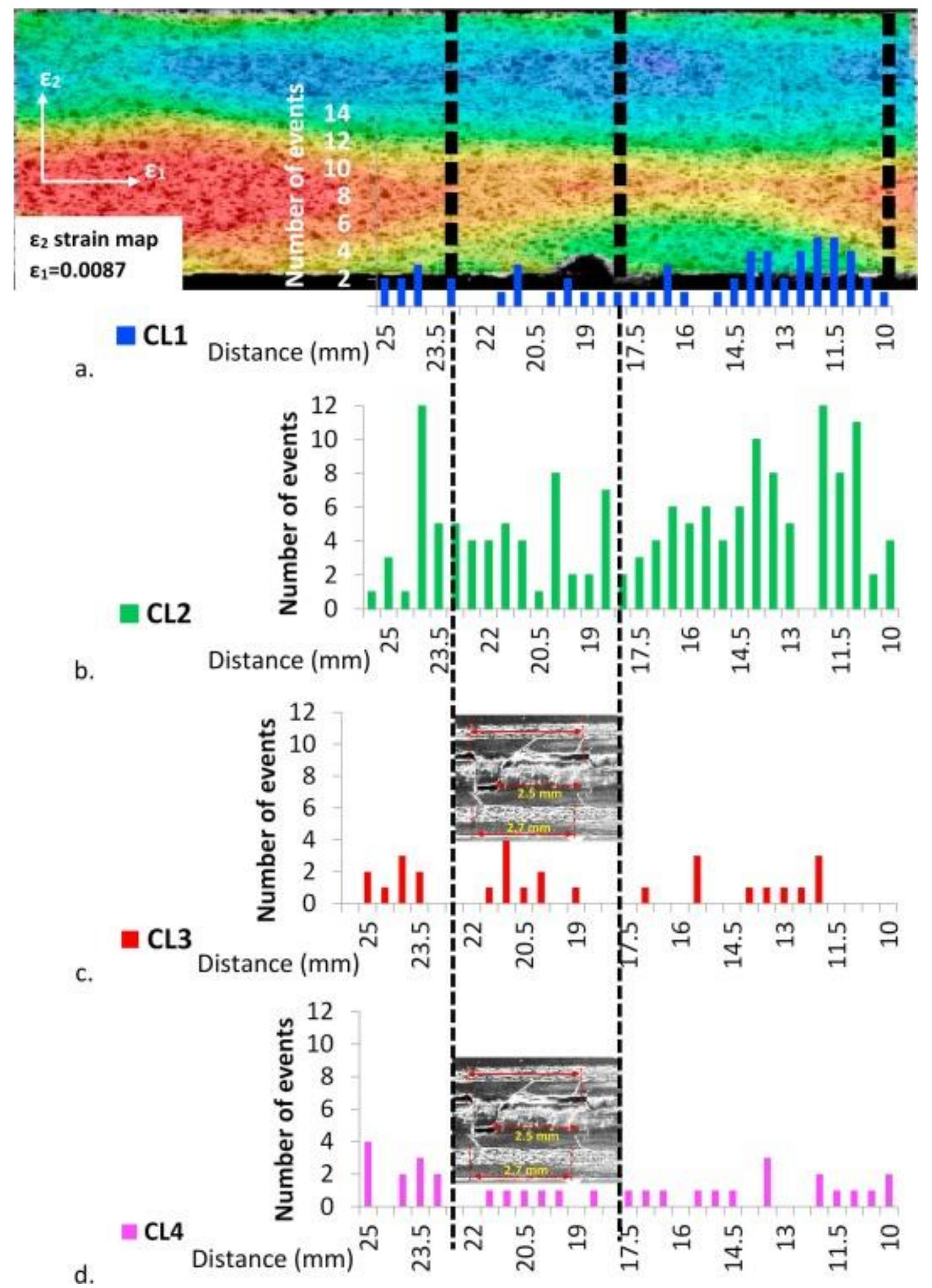

Fig. 7. Distance of clusters to AE sensor on [-452/02/+452/902]s laminate.

Fig. 7.a presents the agreement between macro delamination and its AE detection. It is seen that the number of CL1 events, supposed to represent macro delaminations, is the highest in the region 10$14 \mathrm{~mm}$ in Fig. 7.a. DIC strain map shows that macro delaminations initiate around this region of the laminate. Also, there are larger delaminations in 10-14 $\mathrm{mm}$ region of the gauge length, (please refer to $\varepsilon 2$ legend in Fig. 6). Fig. 5.(a-3) shows that high number of CL1 events start to be recorded from 
0.0061 strain at $8-9 \mathrm{~mm}$ away from the sensor, then it propagates to $10-12 \mathrm{~mm}$ away at around 0.0067 strain level, afterwards it is distributed to further regions. At the end of the test, there seems a large delamination between $45^{\circ}$ layers and $90^{\circ}$ layers in the edge observation region in Fig. 6 . Its correspondence in Fig. 7.a shows that there is a gap at $20 \mathrm{~mm}$ and $22.5 \mathrm{~mm}$ distances. This can be due to discrepancy between AE detection and real location. However, it can also be due to a physical reason: In Fig. 6, distance of the second transverse crack in edge observation region, the one on left, is around $21-22.5 \mathrm{~mm}$ away from the AE sensor at 0.0080 strain. There are micro delaminations and transverse cracks already present at this strain level. Final failure modes are separation of $45^{\circ}$ plies from $90^{\circ}$ plies and separation within mid- $90^{\circ}$ plies from the pre-induced transverse cracks in these mid-plies. Prior damage mode, separation of $90^{\circ}$ layers from $45^{\circ}$ layers, is delamination and that is consistent with occurrence of CL1 but the latter is not really delamination. That's why the AE properties of this separation might not be recorded within CL1 at around $22.5 \mathrm{~mm}$ distance in Fig. 7.a.

$\mathrm{CL} 2$ is supposed to represent micro delaminations that occur everywhere in the specimens. That's why it has the highest number of events, evenly distributed in Fig. 7.b.

$\mathrm{CL3}$ and CL4 are the clusters representing the matrix cracks in $90^{\circ}$ and $45^{\circ}$ plies. Distance between these cracks is $2.5-3 \mathrm{~mm}$ as seen in Fig. 7.c and Fig. 7.d. Periodicity of these events with a period close to $3 \mathrm{~mm}$ for $\mathrm{CL} 3$ and $2 . . .3 \mathrm{~mm}$ for CL4, which seem to correlate with the optical observations.

\section{2. $[902 /-452 / 02 /+452] s$ laminate}

Second laminate in consideration is [902/-452/02/+452]s. Fig. 3.b shows that weighted frequency values of $A E$ events for this lay-up lie below $400 \mathrm{kHz}$, whereas amplitude values are distributed widely. Frequency content is not statistically representative for [902/-452/02/+452]s but amplitude is a selective feature. Optimal cluster number is found to be three. Clusters are not separated so distinctly by amplitude as in previous laminate type. Only the boundary for high amplitude cluster (CL1) is consistent for all tests: it is around $75 \mathrm{~dB}$. Accumulation of clusters throughout the test with respect to amplitude values can be seen in Fig. 8 and damage accumulation is shown in Fig. 9. Edge observation region in Fig. 9 is between $20 . .25 \mathrm{~mm}$, but due to the $1 \mathrm{~mm}$ error between real damage location and AE detection, $19 . .26 \mathrm{~mm}$ is taken into consideration in Fig. 8.b. For this laminate type, $\varepsilon 2$ strain map does not provide useful information for damage mode identification. So, surface cracks are shown instead of $\varepsilon 2$ strain map in Fig. 9. 


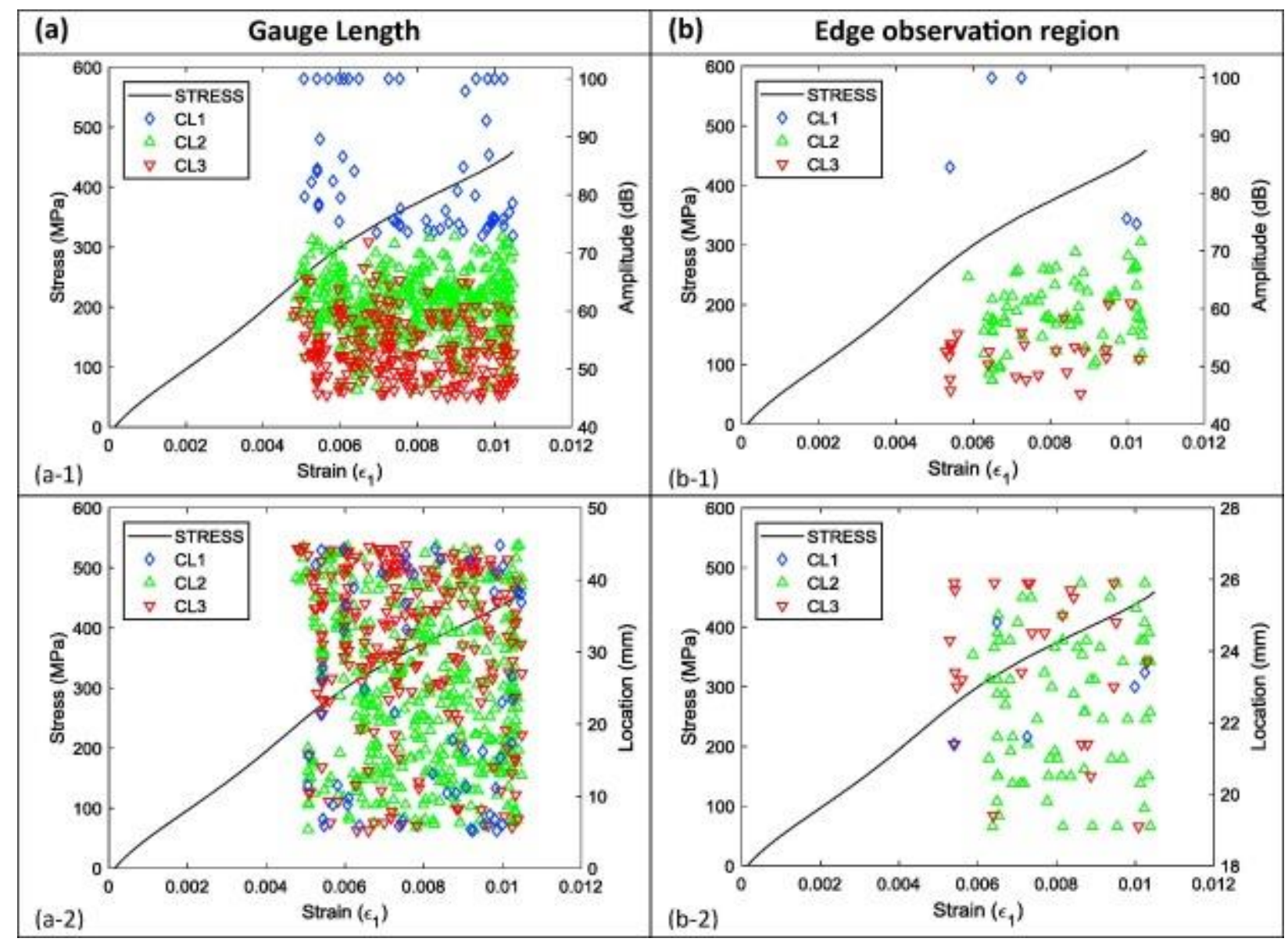

Fig. 8. Accumulation of $A E$ clusters throughout the test in $[902 /-452 / 02 /+452] s$ laminate: (a) full gauge length; (b) edge observation region only; (1) events amplitude; (2) events location. 


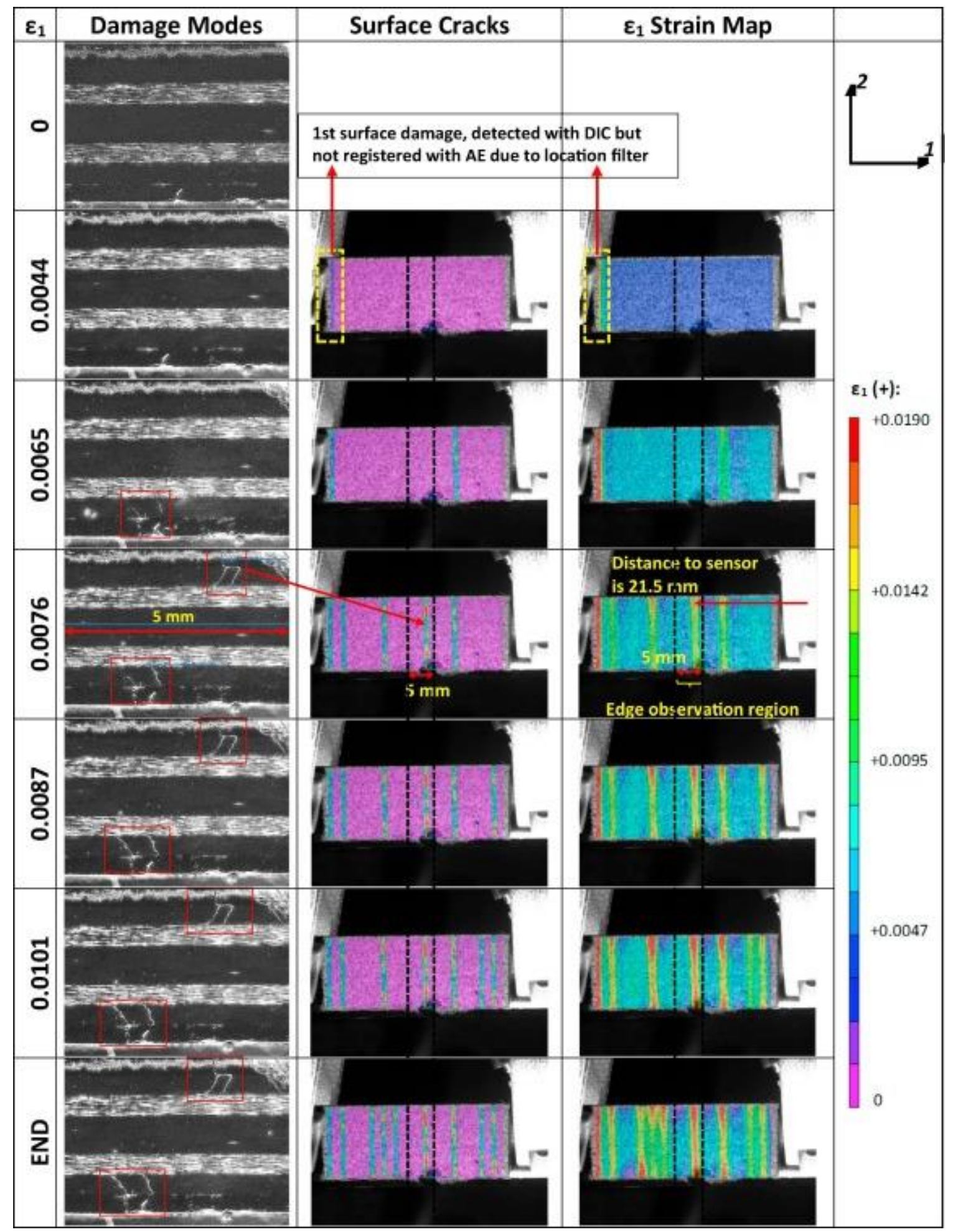

Fig. 9. Damage accumulation in [902/-452/02/+452]s.

Fig. 8.a shows that first AE events are recorded around 0.0048 strain level in gauge length. However, it is seen in Fig. 9 that the first damage is detected at 0.0044 strain level with DIC but was most probably filtered out from the $A E$ registration, as the damage site is too close to the sensors $(<5 \mathrm{~mm}$ distance). Surface cracks can be clearly identified with DIC in Fig. 9. These cracks cause damage in adjacent $-45^{\circ}$ plies immediately with delamination between them as seen at 0.0065 strain in Fig. 9 . 
Damage initiates in surface $90^{\circ}$ plies, reaching adjacent $-45^{\circ}$ plies and evolve through $0^{\circ}$ plies as in 0.0072 strain in Fig. 9. A correlation between DIC deformation maps and edge observation can be done at 0.0076 strain for the top $90^{\circ}$ surface layer. The measured distance of the crack to AE sensor is $21.5 \mathrm{~mm}$. Surface damages at 0.0065 and 0.0076 strain are registered with highest amplitude. Levels of the corresponding events in CL1 has the highest value $(100 \mathrm{~dB}$, which is the maximum set by the AE system) (see Fig. 8.(b-1), 0.0065 and 0.0076 strain). CL1 most probably represents surface cracks. Also, their distances to the AE sensor are 24.5 and $21.4 \mathrm{~mm}$ with respect to AE detection (see Fig. 8.(b-2), 0.0065 and 0.0076 strain) which is highly consistent with measurement.

Meanwhile, there are multiple AE events recorded with lower amplitude levels, belonging to other clusters, CL2 and CL3. Source of these events is not fully clear. Most probably, they are caused by damage in adjacent $-45^{\circ}$ plies and delamination between $90^{\circ} \%-45^{\circ}$ interfaces.

A correlation between surface damage and CL1 is presented in Fig. 10. When an event from CL1 is recorded, corresponding damage is captured with one of optical observation techniques as shown in Fig. 10.a. Some AE events do not correspond to an optical identification. That is probably because they occur at the opposite surface of the laminate which is not monitored by DIC. Fig. 10.b presents a correlation between the damage present at the end of the test with AE location detections.

Overall, there is good agreement between position of the events in the high amplitude cluster, CL1, and optical detections. 


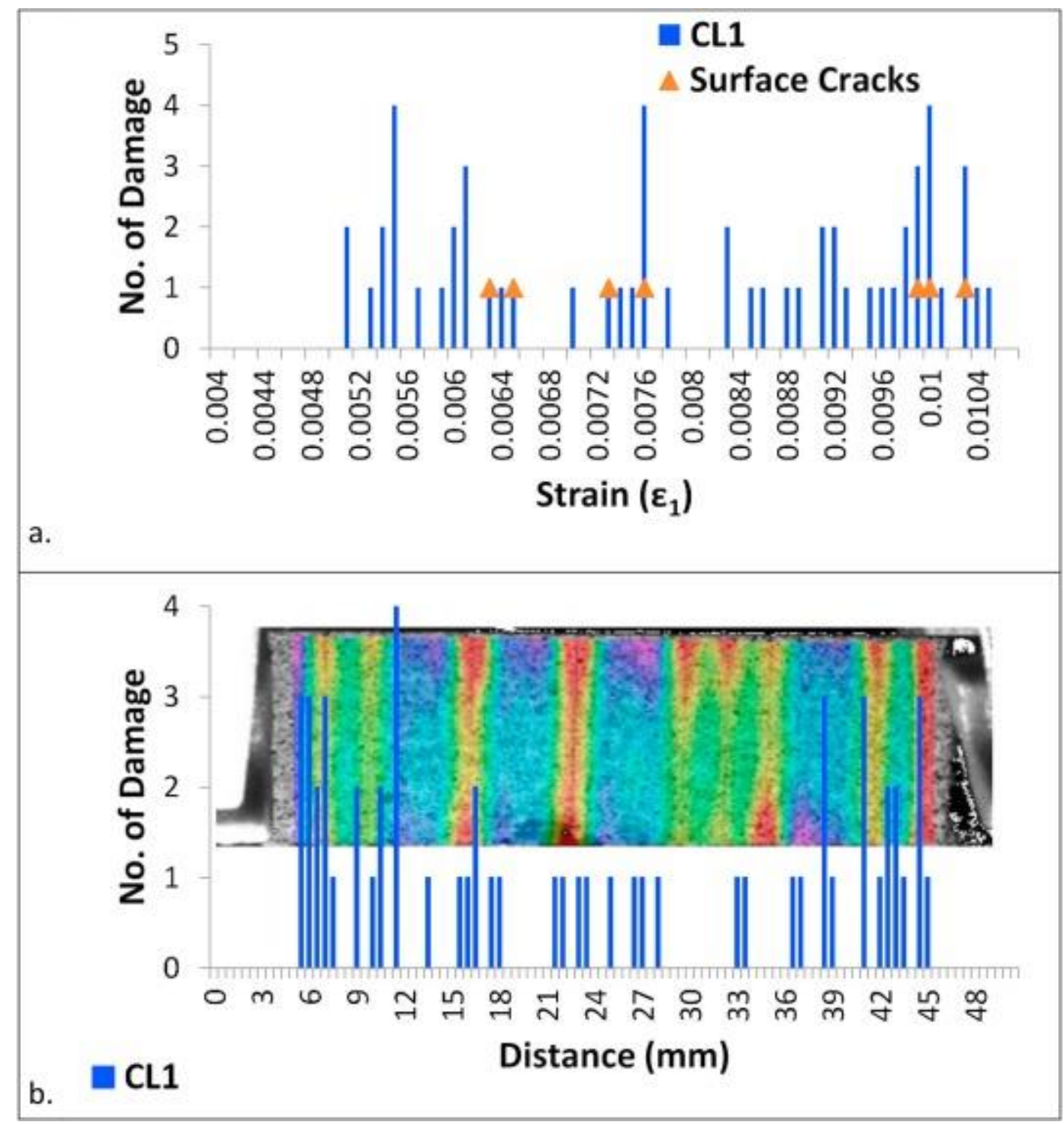

Fig. 10. (a) Comparison of CL1 with optical detection (b) Surface cracks through the specimen gauge length at the end of the test and its comparison with $A E$ detections throughout all the test in $[902 /-452 / 02 /+452] s$.

\section{3. $[02 /+452 / 902 /-452] s$ laminate}

Fig. 3 shows that the number of high frequency events is very high in [02/+452/902/-452]s laminate. The weighted frequency parameter is statistically representative for this laminate type. Average values for cluster boundaries from five tests and separation of clusters from a representative test are shown in Fig. 11.a and b respectively. Very consistent and well-separated clusters are obtained. 


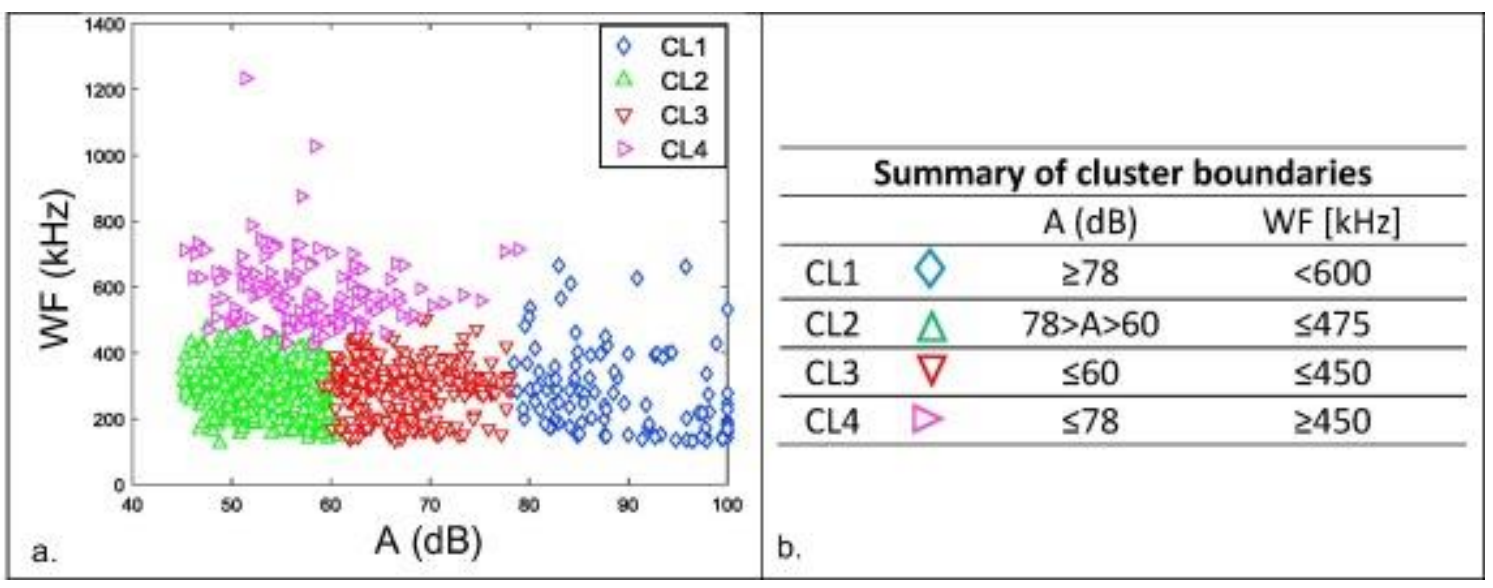

Fig. 11. (a) Distribution of AE clusters in a representative test (b) Summary of cluster boundaries from five tests for $[02 /+452 / 902 /-452]$ s.

DIC strain maps do not provide a helpful information for any surface damage, since surface plies are laid in $0^{\circ}$ direction and no cracks appear in these plies until the end of the tests. It means that only micro damage modes in the inner plies are present in [02/+452/902/-452]s laminate up to $90 \%$ of ultimate strength. Accumulation of AE clusters in the whole gauge length and the edge observation region are shown in Fig. 12. Location distribution of clusters in Fig. 12.(a-3) shows that clusters are well dispersed to the whole gauge length of the specimens. It means that damage modes induced at edge observation region are representative. The $5 \mathrm{~mm}$ edge observation region occupies position $20 \ldots 25 \mathrm{~mm}$ from the AE sensor. A transverse crack in upper $90^{\circ}$ ply almost goes out of view of the edge observation region through the end of the test. Therefore, edge observation region is considered as $20 \ldots 26 \mathrm{~mm}$ distance from AE sensor in Fig. 12.(b-3). 


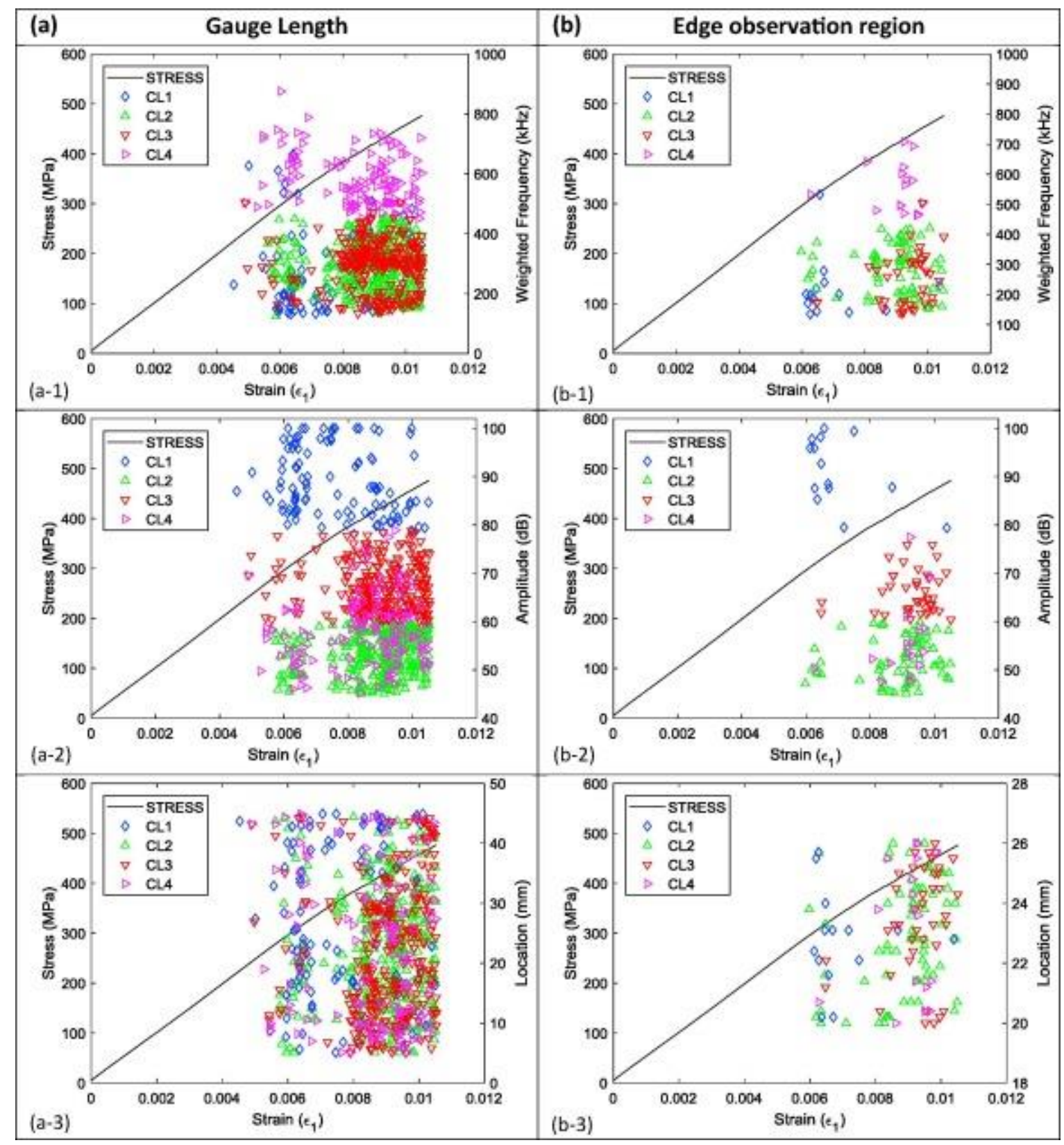

Fig. 12. Accumulation of $A E$ clusters throughout a test in $[02 /+452 / 902 /-452]$ s laminate: (a) full gauge length; (b) edge observation region only; (1) events amplitude; (2) events weighted frequency; (3) events location.

The number of $A E$ events in CL1 is higher than in other clusters through the gauge length as shown in Fig. 12.a. When the edge observation region is taken into consideration only, it is seen that the first registered events belong to CL1 in Fig. 12.b as well. Then CL1 almost disappears in the edge observation region after 0.0080 strain. Meanwhile, the number of events from other clusters increase as seen in Fig. 12.b.

Fig. 13 shows damage accumulation in [02/+452/902/-452]s laminate. When transverse cracks in $90^{\circ}$ plies (shown in red rectangles) occur, it causes delaminations at $90^{\circ} /-45^{\circ}$ and $90^{\circ} \%+45^{\circ}$ intersections at the same time. Transverse cracks in adjacent $\pm 45^{\circ}$ plies do not induce at the same time. First transverse crack induces at 0.0063 strain in upper $90^{\circ}$ plies and the second one occurs at 0.0064 strain in Fig. 13 . Only transverse cracks in $90^{\circ}$ plies are seen until 0.0083 strain level. First damage in lower $+45^{\circ}$ plies initiates at this strain level but it becomes more visible at 0.0084 strain, 
shown within yellow circles in Fig. 13. At the same time two more transverse cracks occur in $90^{\circ}$ plies. Off-axis crack in $+45^{\circ}$ plies reaches to adjacent $0^{\circ}$ plies and another off-axis crack in mid $-45^{\circ}$ plies occurs at 0.0090 strain. Test ends at 0.0105 strain and more off-axis cracks occur in lower and upper $+45^{\circ}$ plies as shown in Fig. 13.

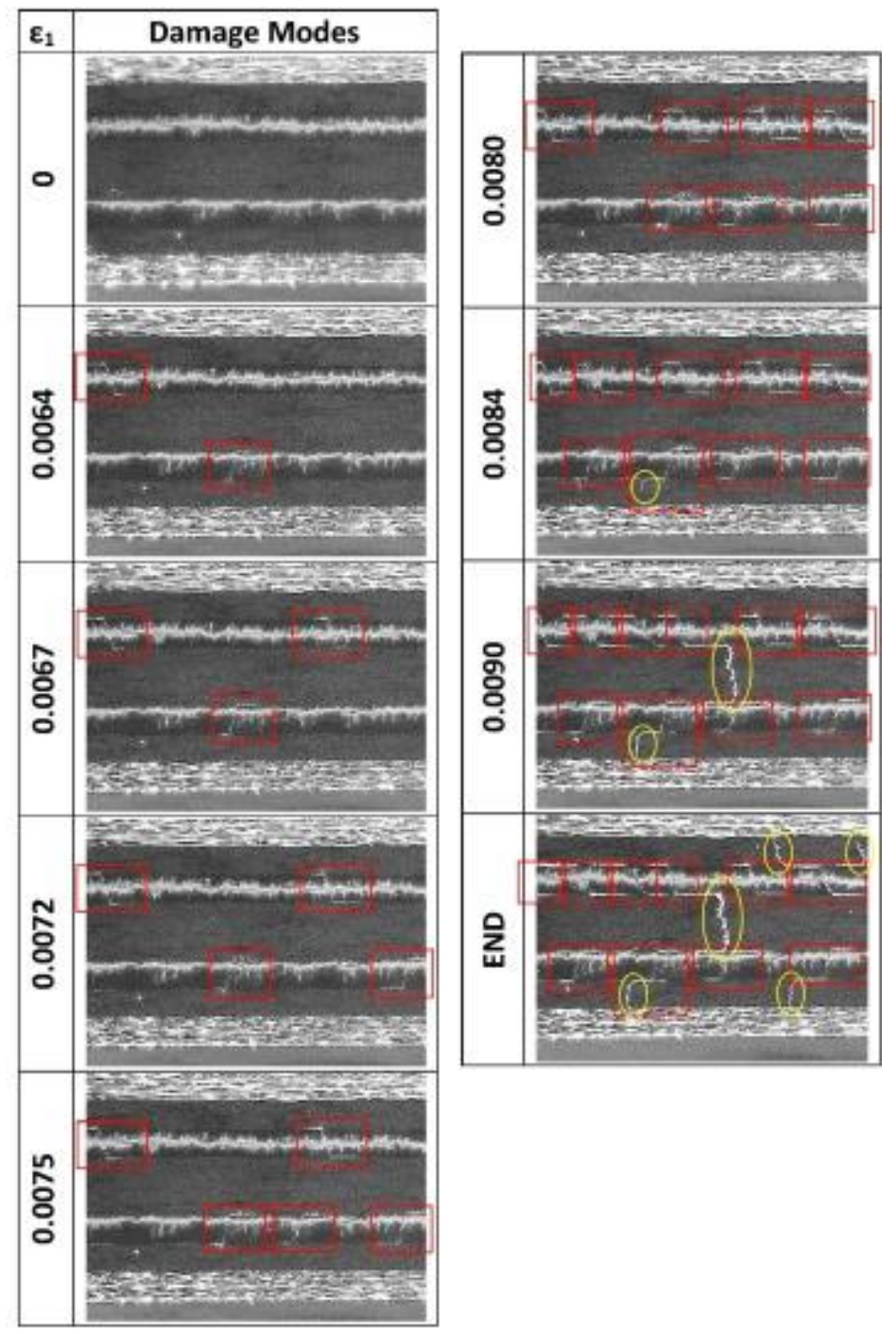

Fig. 13. Damage accumulation in $[02 /+452 / 902 /-452] s$.

There is a good agreement between the accumulation of high number of CL1 events in Fig. 12.b and accumulation of transverse cracks in $90^{\circ}$ plies in Fig. 13 until 0.0080 strain. This is supported by Fig. 14.a where each transverse crack in $90^{\circ}$ plies corresponds to an event from CL1 until 0.0076 strain but subsequent cracks do not necessarily match with CL1 events. High frequency clusters correspond to transverse cracks in the inner $90^{\circ}$ and $+45^{\circ}$ plies in $[-452 / 02 /+452 / 902] s$. By taking this into consideration, correlation between $\mathrm{CL} 4$ and transverse cracks are compared for [02/+452/902/-452]s laminate in Fig. 14.b. Interestingly it is seen that transverse cracks in $90^{\circ}$ plies after 0.0079 strain are highly consistent with CL4. This is also the case in all the tests with AE + DIC + microscopy observations. 


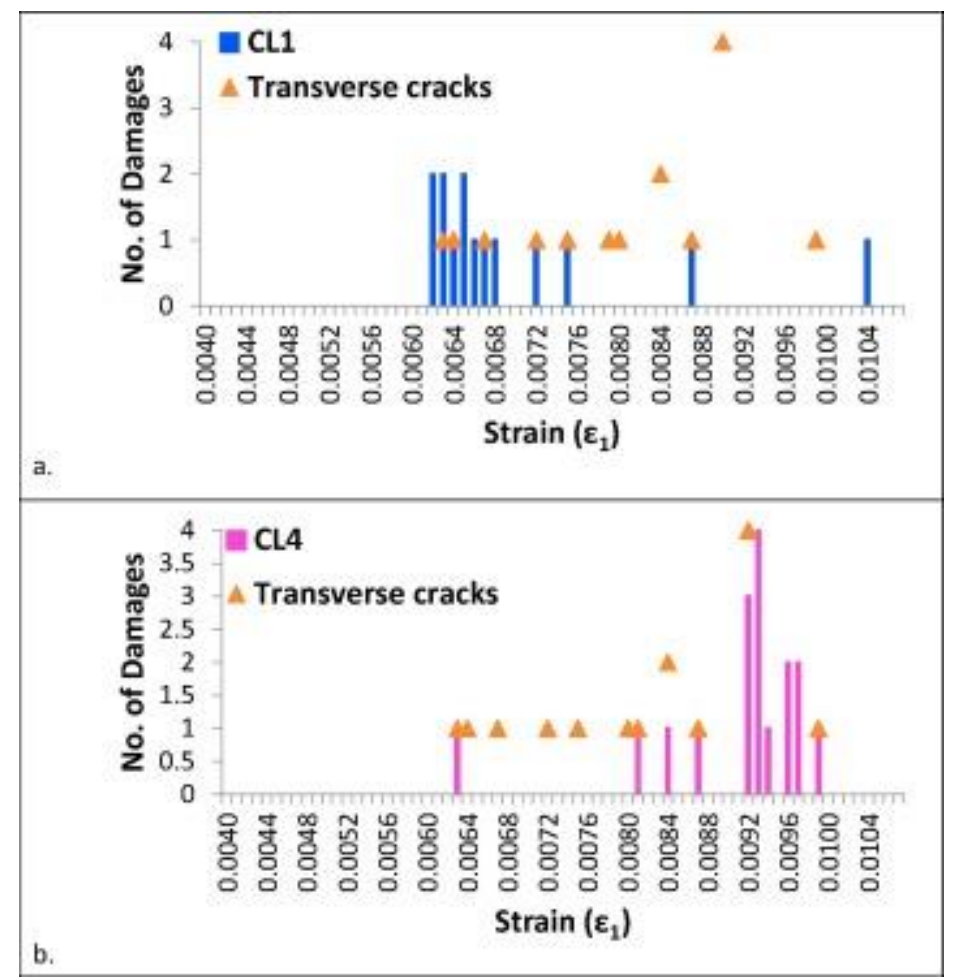

Fig. 14. Comparison of transverse cracks in $90^{\circ}$ plies (a) with CL1 (b) with CL4.

On the other hand, number of events in CL3, which has intermediate amplitude level, increases after 0.0080 strain in Fig. 12. Meanwhile, off-axis cracks in $\pm 45^{\circ}$ plies initiate at 0.0083 strain as seen in the edge observation (Fig. 13). It is highly possible that this damage initiates near or at unpolished edge of the specimen, then propagates to polished edge observation region in Fig. 13 . This correspondence shows that events in CL3 represent off-axis cracks in $\pm 45^{\circ}$ plies. Initiation of damage in $\pm 45^{\circ}$ plies at around this level possibly causes a change in wave propagation properties of damage modes in [02/+452/902/-452]s laminate. So, it can be said that transverse cracks in $90^{\circ}$ plies correspond to high amplitude AE events (CL1) before the initiation of damage in $\pm 45^{\circ}$ plies whereas it shifts to high frequency AE events (CL4) after the initiation of damage in $\pm 45^{\circ}$ plies. Finding the physical reasons of this situation is left as a future work. Finally, cluster with low amplitude and low frequency properties correspond to micro delaminations between $90^{\circ} / \pm 45^{\circ}$ which is distributed to overall specimen gauge length.

\section{4. $[+452 / 902 /-452 / 02] s$ laminate}

Last laminate in consideration is is [+452/902/-452/02]s. Fig. 3.d shows that general characteristics of $A E$ are high amplitude events with low frequency values. It is similar to [902/-452/02/+452]s. It seems that as $90^{\circ}$ plies approach the surface, frequency values of registered events become lower. Three meaningful clusters are obtained for this laminate type, as [902/-452/02/+452]s. Since the weighted frequency or even any other frequency parameter values are not distributed to large extent, clusters can be separated well with respect to amplitude as shown in Fig. 15. Amplitude boundaries are similar to $[02 /+452 / 902 /-452] \mathrm{s}$. 


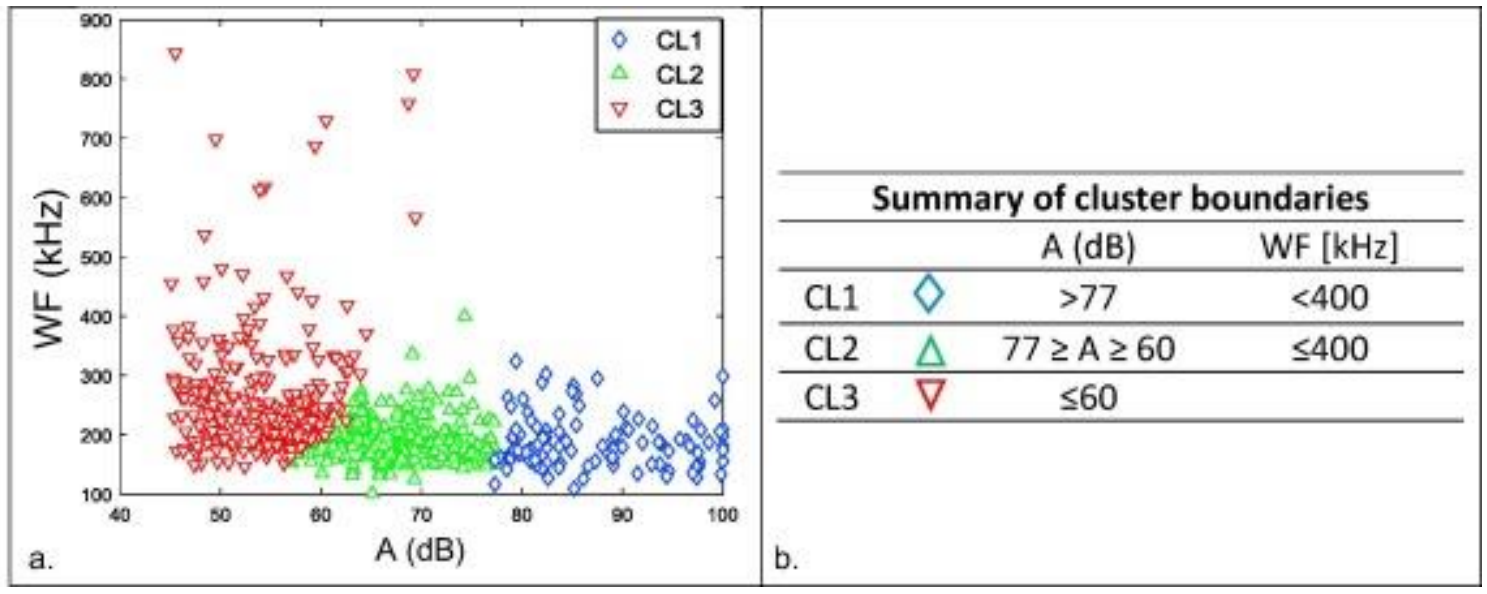

Fig. 15. (a) Distribution of AE clusters in a representative test (b) Summary of cluster boundaries from five tests of [+452/902/-452/02]s.

Accumulation of clusters throughout the test with respect to amplitude is presented in Fig. 16 (frequency parameters are not selective). First events are registered at 0.0048 strain as shown in Fig. 16.a. These events are mostly registered at distances higher than $30 \mathrm{~mm}$ and lower than $20 \mathrm{~mm}$ as seen in Fig. 16.(a-2), whereas the distance of edge observation region is between 21 and $26 \mathrm{~mm}$. Registration of first events in this region starts around 0.0060 strain level as shown in Fig. 16.(b-2). Events in all clusters are initiated at the same time.

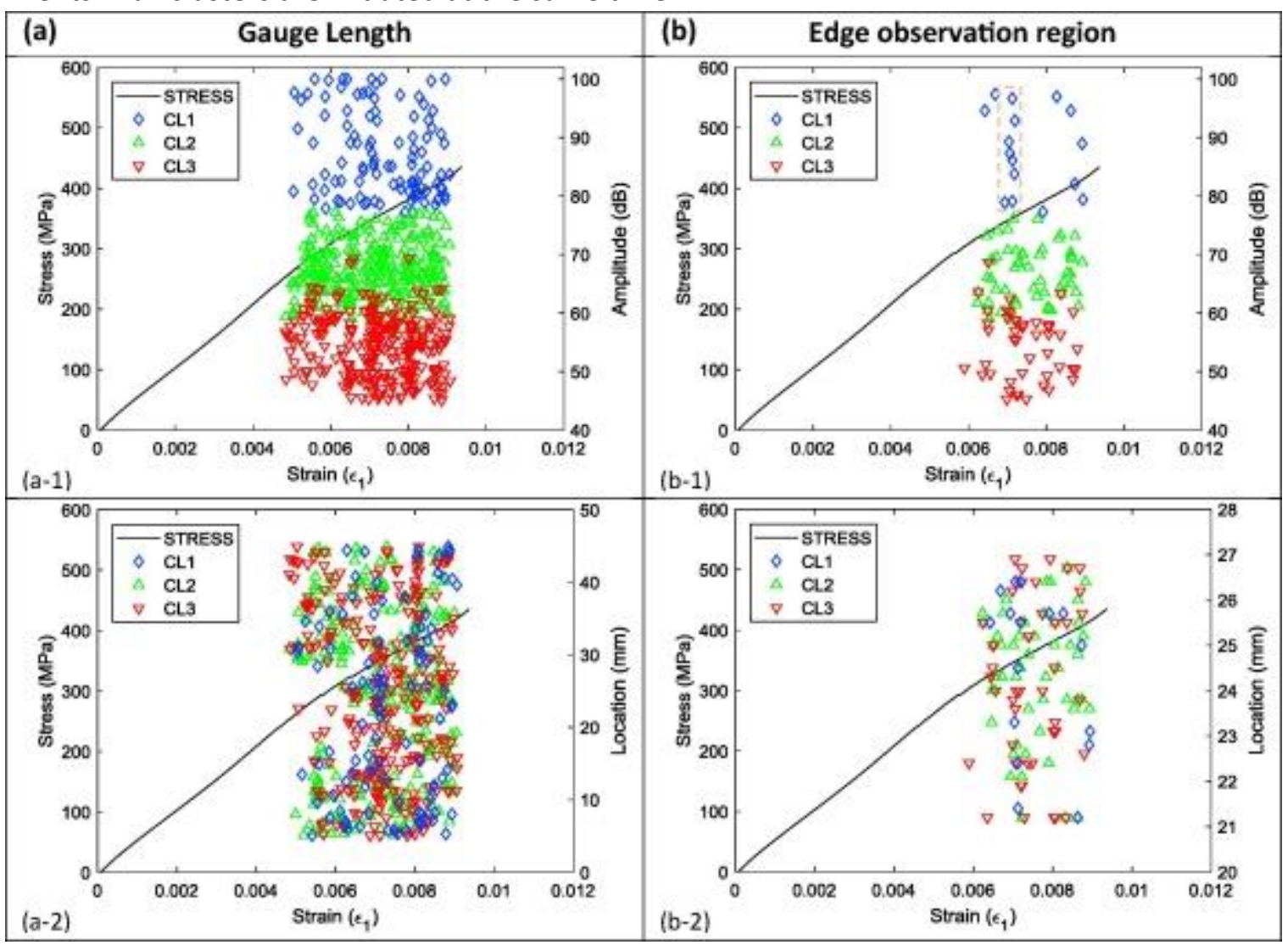

Fig. 16. Accumulation of AE clusters throughout a test in [+452/902/-452/02]s laminate: (a) full gauge length; (b) edge observation region only; (1) events amplitude; (2) events location. 
The first damage, seen in the edge observation region, is a transverse crack in upper $90^{\circ}$ plies at 0.0065 strain (Fig. 17). This damage mode can also be noticed from $\varepsilon 1$ strain map in Fig. 17. Light blue coloured regions in $\varepsilon 1$ strain map represent higher local strain values than average at 0.0065 strain. These are the regions where transverse cracks occur in $90^{\circ}$ plies adjacent to surface. It is very similar to Sause's findings where transverse cracks in $90^{\circ}$ ply, just behind the surface of a [0/90]s laminate, was detected by the strain concentrations in DIC strain map [35]. However, AE events registration in the edge observation region start earlier, at 0.0062 strain. This may be due to the fact that, cracking may start on the other side of the specimen. As in previous laminate types, transverse cracks in $90^{\circ}$ plies occur with delaminations between adjacent $\pm 45^{\circ}$ plies. Then, first crack in surface $+45^{\circ}$ layer is seen at 0.0069 strain in Fig. 17. Immediately after, this surface crack reaches the opposite edge at 0.0070 strain and two transverse cracks occur in lower $90^{\circ}$ plies at the same time as seen in Fig. 17. Second surface crack occurs at 0.0072 strain and passes through the edge observation region as seen from DIC strain maps in Fig. 17. 0.0073 is the strain level when damage in $-45^{\circ}$ plies become visible. Then another transverse crack in lower $90^{\circ}$ plies occurs at 0.0077 strain. Two more surface cracks occur at the same time at 0.0083 strain level in Fig. 17. Delaminations coming from the left side of the $90^{\circ} /-45^{\circ}$ interface becomes highly visible at 0.0086 strain and causes another crack in lower $-45^{\circ}$ plies. Damage distribution seen from the edge observation region and DIC strain map at the end of the test is same with 0.0086 strain. 


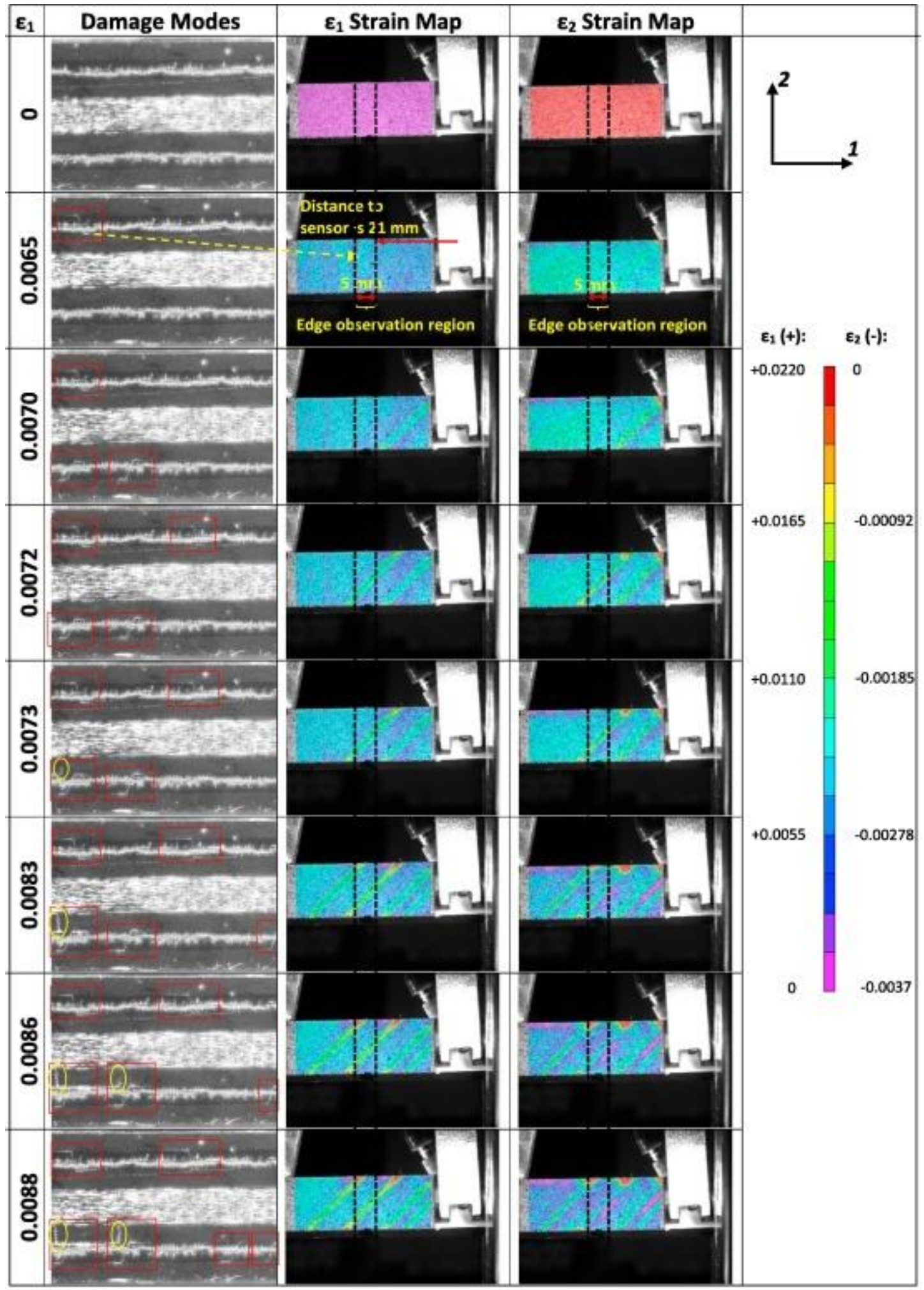

Fig. 17. Damage accumulation in [+452/902/-452/02]s.

According to the results of [902/-452/02/+452]s, an AE event from surface is registered with high amplitude values during tests. It can be said that CL1 events in Fig. 17 represent damage in surface $+45^{\circ}$ layers. Early registered events in Fig. 16. (a-2) do not contain much CL1 events until around 0.0070 strain. There are no surface cracks seen until this strain level of test in Fig. 17. In addition to this, successive events recorded around 0.0072 strain and shown within a dashed box in Fig. 16.(b-1) 
represent the passage of the second surface crack through the edge observation region in Fig. 17. It is also seen in Fig. 16. (b-2) that CL1 events recorded around 0.0072 strain is distributed through the edge observation region from $21 \mathrm{~mm}$ to $26 \mathrm{~mm}$. It is consistent with surface crack passing from through the width of the edge observation region in DIC strain map in Fig. 17.

Early CL2 events are recorded at $24 \mathrm{~mm}$ distance from the sensor until around 0.0072 strain as shown in Fig. 16.(b-2). First three transverse cracks in $90^{\circ}$ plies are seen to occur near the end of the edge observation region until 0.0072 strain in Fig. 17. Its distance to AE sensor is around $25-26 \mathrm{~mm}$. Then a new transverse crack occurs near the closer side of the edge observation region at around 0.0073 strain. It is highly possible that CL2 events between 22 and $23 \mathrm{~mm}$ away from the sensor, recorded after 0.0071 strain in Fig. 16.(b-2) represent the evolution of transverse crack from the unpolished edge of the specimen through the edge observation side of the specimen. Thus, CL2 represents transverse cracks in $90^{\circ}$ plies.

CL3 events with low amplitude and relatively high frequency properties are believed to represent delaminations at $90^{\circ} /-45^{\circ}$ interface and damage in inner $-45^{\circ}$ plies. They are mostly registered near or with CL2 in edge observation region in Fig. 16.(b-2). Moreover, damage in $-45^{\circ}$ plies induce from the delaminations at $90^{\circ} /-45^{\circ}$ interface. However, strong evidences cannot be presented for its correlation and also damage in $-45^{\circ}$ plies. Because, wave propagation properties in this laminate does not enable to distinguish $\mathrm{AE}$ correspondence of damage in the inner $-45^{\circ}$ plies as in [02/+452/902/-452]s lay-up configuration.

4. Summary of the damage sequence in QI laminates

In Sections 3.1-3.4 sequence of the damage development and corresponding characteristics of the AE events for four QI laminate types were established and discussed. Table 3 summarizes this data.

Table 3. Damage sequence and their AE characteristics in each laminate type.

\begin{tabular}{|c|c|c|c|c|c|}
\hline \multirow[t]{2}{*}{ Laminate } & \multirow{2}{*}{\multicolumn{2}{|c|}{ Damage sequence }} & \multicolumn{2}{|c|}{ AE Characteristics } & \multirow{2}{*}{ Strain Ranges } \\
\hline & & & $A(d B)$ & WF $[\mathrm{kHz}]$ & \\
\hline \multirow{4}{*}[-45_{2}/0_{2}/+45_{2}/90_{2}]{$_{s}$} & 1. & Transverse cracking in $90^{\circ}$ plies & $<66$ & $>480$ & $0.0048-0.0063$ \\
\hline & 2. & Micro delamination at $90 /+45$ interface & $<66$ & $\leq 260$ & $0.0049-0.0102$ \\
\hline & 3. & Transverse cracking in $+45^{\circ}$ plies & $<66$ & $260 \ldots 480$ & $0.0050-0.0080$ \\
\hline & 4. & Macro delamination & $\geq 66$ & $\leq 260$ & $0.0061-0.0107$ \\
\hline \multirow{3}{*}[90_{2}/-45_{2}/\mathrm{O}_{2}/+45_{2}]{$_{s}$} & 1. & Transverse cracking in surface $90^{\circ}$ plies & $>75$ & & $0.0048-0.0105$ \\
\hline & 1. & Micro delamination between $90 /-45$ interface & & & \\
\hline & 1. & Transverse cracking in $-45^{\circ}$ plies & & & \\
\hline \multirow{4}{*}[0_{2}/+45_{2}/90_{2}/-45_{2}]{$_{5}$} & \multirow{2}{*}{1.} & \multirow{2}{*}{ Transverse cracking in $90^{\circ}$ plies } & $\geq 78$ & $<600$ & $0.0060-0.0080$ \\
\hline & & & $\leq 78^{*}$ & $\geq 450^{*}$ & $0.0080-0.0100$ \\
\hline & 2. & Micro delamination at $90 /+45$ interface & $\leq 60$ & $\geq 450$ & $0.0061-0.0101$ \\
\hline & 3. & Transverse cracking in $\pm 45^{\circ}$ plies & $60 . . .78$ & $\leq 475$ & $0.0080-0.0101$ \\
\hline$\because$ AE ch & acter & s change from the above to these values with initiati & f Transve & cracking in : & plies \\
\hline \multirow{4}{*}[+45_{2}/90_{2}/-45_{2}/0_{2}]{$_{s}$} & 1. & Transverse cracking in $90^{\circ}$ plies & $60 \ldots 77$ & $\leq 400$ & $0.0048-0.0088$ \\
\hline & 2. & Micro delaminations at $90 / \pm 45$ interface & $\leq 60$ & & $0.0048-0.0088$ \\
\hline & 3. & Damage in surface $+45^{\circ}$ plies & $>77$ & $<400$ & $0.0069-0.0083$ \\
\hline & 4. & Transverse cracking in $-45^{\circ}$ plies & $\leq 60$ & & $0.0073-0.0088$ \\
\hline
\end{tabular}

Five different damage modes are observed in this study that are highlighted with different colours in Table 3. However, no "fibre breaks" were monitored, since this failure mode probably causes lower amplitude than $40 \mathrm{~dB}$ or it is out of the strain range that the specimens are loaded. These results indicate that high frequency $A E$ events do not necessarily represent fibre breaks. First of all, 
transverse cracks occur in $90^{\circ}$ plies which is followed by micro delaminations at $90 / \pm 45$ interfaces and then, transverse cracks propagate to $\pm 45^{\circ}$ plies. This damage sequence is same in each laminate type. In fact they are the only damage modes observed in [902/-452/02/+452]s, $[02 /+452 / 902 /-452] s$ and $[+452 / 902 /-452 / 02] s$ laminates. Damage in surface $+45^{\circ}$ plies can be considered as transverse cracking at $45^{\circ}$ plies but it is shown with a different colour in Table 3 due to their different $\mathrm{AE}$ characteristics from damage in the inner $45^{\circ}$ plies. Aside from these three laminates, damage progresses with macro delaminations in [-452/02/+452/902]s laminate. AE detection strain levels are considered for strain ranges in Table 3. Transverse cracks in $90^{\circ}$ plies initiate at 0.0048 strain in $[-452 / 02 /+452 / 902] s$ laminate and micro delaminations at $90 / \pm 45$ interface occurs immediately after 0.0049 strain. Then damage propagates to $+45^{\circ}$ plies at 0.0050 strain, followed by macro delamination between $90^{\circ}$ and $+45^{\circ}$ plies which initiates at 0.0061 strain. Similarly, transverse cracks in $90^{\circ}$ plies initiate in [902/-452/02/+452]s laminate at 0.0048 strain in form of surface cracks. Micro delamination at 90/-45 interface and transverse cracking at $-45^{\circ}$ plies occur at the same time with $90^{\circ}$ plies. Damage initiation level is delayed in [02/+452/902/-452]s laminate. Initiation of transverse cracks in $90^{\circ}$ plies are seen to occur together with micro delaminations at 0.0060 and 0.0061 strain levels respectively. Then, propagation of transverse cracks in $\pm 45^{\circ}$ plies is detected at 0.0080 strain levels. AE records for [+452/902/-452/02]s laminate indicates that all damage types are seen at the same threshold level of 0.0048 strain but observations provide a clear sequence. Therefore, damage sequence is considered with respect to observations. Transverse cracks in $90^{\circ}$ plies are observed at 0.0065 strain level. Then damage propagates to $+45^{\circ}$ plies and damage initiation in these plies occur as surface cracks at 0.0069 strain level. Finally, damage in inner $-45^{\circ}$ plies are seen to be started at 0.0073 strain.

Not only damage threshold levels but also the AE characteristics of damage modes are different in each laminate type. It is found that if $90^{\circ}$ or $45^{\circ}$ plies are inner plies, transverse cracks in these plies have high frequency-low amplitude characteristics and large separation of these plies are registered with highest amplitude events in $[-452 / 02 /+452 / 902] s$. When $90^{\circ}$ or $45^{\circ}$ plies are on surface, damage in these plies are registered with high amplitude events as in [902/-452/02/+452]s and [+452/902/-452/02]s. Interesting situation is observed for [02/+452/902/-452]s in which transverse cracks in $90^{\circ}$ plies are registered with high amplitude-low frequency events and then with high frequency-low amplitude events after the initiation of damage in $\pm 45^{\circ}$ plies, which have mid-level amplitude - low frequency AE characteristics. Regardless of laminate type, micro delaminations are registered with low amplitude-low frequency events. Boundaries of the clusters can be seen with details in Table 3.

\section{Discussion}

First a comment on the fibre breaks detection and observations. We cannot be sure whether the fibre breaks are detected or not in our measurements, and even stronger, that most probably they were not detected. This is because the fibre breaks, as observed, for example by Li et al. [28], are likely to have low amplitude, close to the used AE threshold and not "heard" by the used broadband sensors with relatively low sensitivity. We also cannot observe the fibre breaks with the used optical observations and DIC. Therefore, we could not reach any conclusion of the fibre breaks themselves. Our measurements rather point out that the AE events, which could be interpreted as fibre breaks because of their high frequency parameters, are in reality, as optical/DIC observations prove, correspond to other damage types.

This study shows that AE characteristics of damage modes do not have a "fingerprint" properties and in general does not lead to a general classification as in Table 1. Instead, each lay-up sequence has specific characteristics and cause variation in $A E$ characteristics of damage modes. According to 
Sause [35], the variation in AE characteristics of each damage mode in different laminates are related with two important factors; i) through thickness distance of a damage to sensors (depth of source), ii) deflection time of a signal (source rise time).

Depth of source (damage) or through thickness distance of a damage to AE sensors is an important factor to affect the AE characteristics of a damage. As summarized in Introduction section, there are studies in literature showed that the FFT peak-frequency values of a damage shifts from the high frequency to low frequency and their WT characteristics shifts from SO to AO mode [32], [33], [34], [35], [36], [37].

Secondly, source rise time determines the AE bandwidth of a source (damage). Short rise time causes a broad bandwidth that enables AE signals with high frequency characteristics. It is linked with the size of the crack surface and elastic properties of the damaging material. However, there are no information about successfully measuring the rise time of a real AE source but Sause performed micromechanical FE simulations for $A E$ sources to predict the rise time and hence the $A E$ characteristics of different damage modes within UD laminate models [35]. It was seen that fibre breaks induce in very short rise times and had low amplitude and high frequency characteristics. On the other hand, matrix damage modes had lower frequency characteristics due to the larger crack surface and ductile properties. Simulations also showed that the velocity of a guided wave was higher in fibre directions than in transverse directions or in the matrix.

The findings in this study should be discussed with respect to these two findings. It is obvious that depth of source affects the $A E$ characteristics of damage modes. It is more prominent for transverse cracks in $90^{\circ}$ plies. They have high frequency characteristics in $[-452 / 02 /+452 / 902] s$ and $[02 /+452 / 902 /-452] s$ laminates but low frequency characteristics in $[902 /-452 / 02 /+452] s$ and [+452/902/-452/02]s laminates. This was mentioned in previous studies [32], [33], [34], [35], [36], [37] but strong evidences are presented for complex laminates in this study.

In addition to this, the effect of rise-time should be discussed. It was seen that tension tests of six different cross-ply (XP) laminates resulted with noticeable changes in the cluster boundaries for each damage mechanisms but not the AE characteristics (matrix cracking events were low weighted frequency events and fibre breaks were registered with high weighted frequency events) [35], [36]. Even though six different configurations were tested, the surface plies were $0^{\circ}$ plies in each type and sensors were always placed on the $0^{\circ}$ ply. It means that guided waves of damage modes travelled from the similar paths to the AE sensors. However, in more complex laminates, tested in this study, $A E$ sensors are placed on surface plies, having different fibre orientations. This means that the speed of the sound is different, hence the arrival times and rise times of various damage modes. For example, if $0^{\circ}$ plies are placed between the AE sensors and $90^{\circ}$ plies, guided waves of transverse cracks travels to the sensors quickly, because the $A E$ velocity of guided waves propagate much quicker in $0^{\circ}$ directions as compared to $90^{\circ}$ or $45^{\circ}$ directions. This damage mode has high frequency characteristics in $[-452 / 02 /+452 / 902] s$ and $[02 /+452 / 902 /-452] s$ laminates. On the other hand, it is registered with low frequency characteristics in [902/-452/02/+452]s and [+452/902/-452/02]s laminates. Besides, surface cracks have the highest amplitude characteristics in last two laminate types since they are in contact with $A E$ sensors. These cause considerable changes in the $A E$ classification of damage modes.

Consequently, it can be said that the effect of depth of damage mode to the AE sensor can be seen clearly but the effect of rise-time cannot be evaluated in this study, since the traveling path of the damage modes change in each laminate type. Thus, effect of depth of source seems to be the most 
dominant factor for variation in $\mathrm{AE}$ characteristics of same damage modes than rise-time effect in the light of the findings of this study.

\section{Conclusions}

$A E$ registration technique alone during tension tests is not sufficient for damage mode identification in CFRP composites. Even though k-means++ clustering algorithm can recognise well-separated and dense clusters, it is found that those clusters cannot be unambiguously used to identify the type of the damage which caused the event. This study presents the necessity of multi-instrument optical observations for damage-mode identification and correlation with $A E$ registrations. QI laminates made from UD prepregs are tested. Application of AE registration, optical edge observations and surface strain mapping by DIC method simultaneously during tension tests provides invaluable insight for identifying the damage modes in progressive damage induced in the laminates during testing. The results obtained in this study put the reliability of widely adopted AE based damage mode classifications in question and a new classification scheme is proposed.

Observations in this study prove that high frequency signals are related to transverse matrix cracks in the inner $90^{\circ}$ plies and not fibre breaks as conventionally believed. Three-four cluster groups are found for classification of recorded AE events. However, their structures differ for each laminate. It is seen that low amplitude-high frequency events represent transverse cracks in the inner $90^{\circ}$ and $\pm 45^{\circ}$ plies whereas high amplitude-low frequency events represent damage at surface plies. Cluster groups are correlated to four different damage mode. Damage initiation occurs with transverse cracks in $90^{\circ}$ plies which is followed by micro delaminations at $90 / \pm 45$ interfaces and propagation of transverse cracks to $\pm 45^{\circ}$ plies afterwards. This damage sequence is same in each laminate type but damage progression continues with macro delamination of $90^{\circ} / \pm 45^{\circ}$ plies in $[-452 / 02 /+452 / 902] \mathrm{s}$ laminate. Furthermore, delaminations inside the laminate of a uniform laminate, not containing any artificially introduced defect, can be observed as disturbances in the surface strain maps, which is a novel observation, and as for the authors' knowledge not mentioned before in the open literature. Fibre breaks are not involved in this study since they are not observed with optical instruments. Fibre breaks need more detailed analysis, probably with instruments having higher resolution such as in-situ micro-CT device [56], [57]. Further work which are planned to be published will implement the findings of this study to notched specimens and specimens with different sub-laminate scaling.

\section{Acknowledgements}

Authors acknowledge the support of the Boğaziçi University Research Fund, Istanbul Development Agency (ISTKA), and TUBITAK BIDEB 2214-A under project codes 10020/15A06D3, ISTKA/BIL/2012/58 and 1059B141600673 respectively. S.V. Lomov holds the Toray Chair on Composites at KU Leuven, the support of which is gratefully acknowledged. We also acknowledge Dr. Emin Sunbuloglu and Dr. Erhan Bozdag for providing access to VIC 2D software in Istanbul Technical University.

\section{References}

[1] T.C. Truong, M. Vettori, S. Lomov, I. VerpoestCarbon composites based on multi-axial multi-ply stitched preforms. Part 4. Mechanical properties of composites and damage observation

Compos Part A Appl Sci Manuf, 36 (2005), pp. 1207-1221, 10.1016/j.compositesa.2005.02.004

[2] S.V. Lomov, D.S. Ivanov, T.C. Truong, I. Verpoest, F. Baudry, K. Vanden Bosche, et al.Experimental methodology of study of damage initiation and development in textile composites in uniaxial tensile test 
Compos Sci Technol, 68 (2008), pp. 2340-2349, 10.1016/j.compscitech.2007.07.005

[3] S.V. Lomov, A.E. Bogdanovich, D.S. Ivanov, D. Mungalov, M. Karahan, I. VerpoestA comparative study of tensile properties of non-crimp 3D orthogonal weave and multi-layer plain weave E-glass composites. Part 1: materials, methods and principal results

Compos Part A Appl Sci Manuf, 40 (2009), pp. 1134-1143, 10.1016/j.compositesa.2009.03.012

[4] D.S. Ivanov, S.V. Lomov, A.E. Bogdanovich, M. Karahan, I. VerpoestA comparative study of tensile properties of non-crimp 3D orthogonal weave and multi-layer plain weave E-glass composites. Part 2: comprehensive experimental results

Compos Part A Appl Sci Manuf, 40 (2009), pp. 1144-1157, 10.1016/j.compositesa.2009.04.032

[5] S. Daggumati, W. Van Paepegem, J. Degrieck, T. Praet, B. Verhegghe, J. Xu, et al.Local strain in a 5-harness satin weave composite under static tension: Part II - Meso-FE analysis

Compos Sci Technol, 71 (2011), pp. 1217-1224, 10.1016/j.compscitech.2011.03.020

[6] A.E. Bogdanovich, M. Karahan, S.V. Lomov, I. VerpoestQuasi-static tensile behavior and damage of carbon/epoxy composite reinforced with 3D non-crimp orthogonal woven fabric

Mech Mater, 62 (2013), pp. 14-31, 10.1016/j.mechmat.2013.03.005

[7] S. Barré, M.L. BenzeggaghOn the use of acoustic emission to investigate damage mechanisms in glass-fibre-reinforced polypropylene

Compos Sci Technol, 52 (1994), pp. 369-376, 10.1016/0266-3538(94)90171-6

[8] O. Ceysson, M. Salvia, L. VincentDamage mechanisms characterisation of carbon fibre/epoxy composite laminates by both electrical resistance measurements and acoustic emission analysis

Scr Mater, 34 (1996), pp. 1273-1280, 10.1016/1359-6462(95)00638-9

[9] S.-T. Kim, Y.-T. LeeCharacteristics of damage and fracture process of carbon fiber reinforced plastic under loading-unloading test by using AE method

Mater Sci Eng A, 234-236 (1997), pp. 322-326, 10.1016/S0921-5093(97)00226-8

[10] G. Kotsikos, J.T. Evans, A.G. Gibson, J. HaleUse of acoustic emission to characterize corrosion fatigue damage accumulation in glass fiber reinforced polyester laminates

Polym Compos, 20 (1999), pp. 689-696

[11] M. Bourchak, I.R. Farrow, I.P. Bond, C.W. Rowland, F. MenanAcoustic emission energy as a fatigue damage parameter for CFRP composites

Int J Fatigue, 29 (2007), pp. 457-470, 10.1016/j.ijfatigue.2006.05.009

[12] P.F. Liu, J.K. Chu, Y.L. Liu, J.Y. ZhengA study on the failure mechanisms of carbon fiber/epoxy composite laminates using acoustic emission

Mater Des, 37 (2012), pp. 228-235, 10.1016/j.matdes.2011.12.015

[13] M. Fotouhi, M. Saeedifar, S. Sadeghi, M. Ahmadi Najafabadi, G. MinakInvestigation of the damage mechanisms for mode I delamination growth in foam core sandwich composites using acoustic emission 
Struct Heal Monit, 14 (2015), pp. 265-280, 10.1177/1475921714568403

[14] M. Fotouhi, M.A. NajafabadiAcoustic emission-based study to characterize the initiation of delamination in composite materials

J Thermoplast Compos Mater, 29 (2016), pp. 519-537, 10.1177/0892705713519811

[15] P.J. de Groot, P.A.M. Wijnen, R.B.F. JanssenReal-time frequency determination of acoustic emission for different fracture mechanisms in carbon/epoxy composites

Compos Sci Technol, 55 (1995), pp. 405-412, 10.1016/0266-3538(95)00121-2

[16] C.R. Ramirez-Jimenez, N. Papadakis, N. Reynolds, T.H. Gan, P. Purnell, M. Pharaohldentification of failure modes in glass/polypropylene composites by means of the primary frequency content of the acoustic emission event

Compos Sci Technol, 64 (2004), pp. 1819-1827, 10.1016/j.compscitech.2004.01.008

[17] H.-J. JongTransverse cracking in a cross-ply composite laminate - detection in acoustic emission and source characterization

J Compos Mater, 40 (2005), pp. 37-69, 10.1177/0021998305053507

[18] A. Bussiba, M. Kupiec, S. Ifergane, R. Piat, T. BöhlkeDamage evolution and fracture events sequence in various composites by acoustic emission technique

Compos Sci Technol, 68 (2008), pp. 1144-1155, 10.1016/j.compscitech.2007.08.032

[19] R. Gutkin, C.J. Green, S. Vangrattanachai, S.T. Pinho, P. Robinson, P.T. CurtisOn acoustic emission for failure investigation in CFRP: Pattern recognition and peak frequency analyses

Mech Syst Signal Process, 25 (2011), pp. 1393-1407, 10.1016/j.ymssp.2010.11.014

[20] R. Mohammadi, M.A. Najafabadi, M. Saeedifar, J. Yousefi, G. MinakCorrelation of acoustic emission with finite element predicted damages in open-hole tensile laminated composites

Compos Part B Eng, 108 (2017), pp. 427-435, 10.1016/j.compositesb.2016.09.101

[21] S. Huguet, N. Godin, R. Gaertner, L. Salmon, D. VillardUse of acoustic emission to identify damage modes in glass fibre reinforced polyester

Compos Sci Technol, 62 (2002), pp. 1433-1444, 10.1016/S0266-3538(02)00087-8

[22] N. Godin, S. Huguet, R. Gaertner, L. SalmonClustering of acoustic emission signals collected during tensile tests on unidirectional glass/polyester composite using supervised and unsupervised classifiers

NDT E Int, 37 (2004), pp. 253-264, 10.1016/j.ndteint.2003.09.010

[23] N. Godin, S. Huguet, R. GaertnerIntegration of the Kohonen's self-organising map and k-means algorithm for the segmentation of the AE data collected during tensile tests on cross-ply composites NDT E Int, 38 (2005), pp. 299-309, 10.1016/j.ndteint.2004.09.006

[24] M.G.R. Sause, A. Gribov, A.R. Unwin, S. HornPattern recognition approach to identify natural clusters of acoustic emission signals

Pattern Recognit Lett, 33 (2012), pp. 17-23, 10.1016/j.patrec.2011.09.018 
[25] M.G.R. Sause, T. Muller, A. Horoschenkoff, S. HornQuantification of failure mechanisms in mode-I loading of fiber reinforced plastics utilizing acoustic emission analysis

Compos Sci Technol, 72 (2012), pp. 167-174, 10.1016/j.compscitech.2011.10.013

[26] L. Li, S.V. Lomov, X. Yan, V. CarvelliCluster analysis of acoustic emission signals for 2D and 3D woven glass/epoxy composites

Compos Struct, 116 (2014), pp. 286-299, 10.1016/j.compstruct.2014.05.023

[27] L. Li, S.V. Lomov, X. YanCorrelation of acoustic emission with optically observed damage in a glass/epoxy woven laminate under tensile loading

Compos Struct, 123 (2015), pp. 45-53, 10.1016/j.compstruct.2014.12.029

[28] L. Li, Y. Swolfs, I. Straumit, X. Yan, S.V. LomovCluster analysis of acoustic emission signals for 2D and $3 \mathrm{D}$ woven carbon fiber/epoxy composites

J Compos Mater, 50 (2016), pp. 1921-1935, 10.1177/0021998315597742

[29] V. Carvelli, A. D'Ettorre, S.V. LomovAcoustic emission and damage mode correlation in textile reinforced PPS composites

Compos Struct, 163 (2017), pp. 399-409, 10.1016/j.compstruct.2016.12.012

[30] M. Fotouhi, Najafabadi M. Ahmadilnvestigation of the mixed-mode delamination in polymermatrix composites using acoustic emission technique

J Reinf Plast Compos, 33 (2014), pp. 1767-1782, 10.1177/0731684414544391

[31] M. Saeedifar, M. Fotouhi, M. Ahmadi Najafabadi, H. Hosseini Toudeshky, G. MinakPrediction of quasi-static delamination onset and growth in laminated composites by acoustic emission

Compos Part B Eng, 85 (2016), pp. 113-122, 10.1016/j.compositesb.2015.09.037

[32] M. Hamstad, A. O'Gallagher, J. GaryA wavelet transform applied to acoustic emission signals:

Part 1: Source identification

J Acoust Emiss, 20 (2002), pp. 62-82

[33] J.J. Scholey, P.D. Wilcox, M.R. Wisnom, M.I. FriswellQuantitative experimental measurements of matrix cracking and delamination using acoustic emission

Compos Part A Appl Sci Manuf, 41 (2010), pp. 612-623, 10.1016/j.compositesa.2010.01.008

[34] M.G.R. Sause, M.A. Hamstad, S. HornFinite element modeling of lamb wave propagation in anisotropic hybrid materials

Compos Part B, 53 (2013), pp. 249-257, 10.1016/j.compositesb.2013.04.067

[35] Sause MGR. In Situ monitoring of fiber-reinforced composites theory, basic concepts, methods, and applications; 2016.

[36] Sause MGR, Monden A. Comparison of predicted onset of failure mechanisms by nonlinear failure theory and by acoustic emission. In: 16th Eur. Conf. Compos. Mater., Sevilla: ESCM; 2015.

[37] C. Baker, G.N. Morscher, V.V. Pujar, J.R. LemanskiTransverse cracking in carbon fiber reinforced polymer composites: modal acoustic emission and peak frequency analysis 
Compos Sci Technol, 116 (2015), pp. 26-32, 10.1016/j.compscitech.2015.05.005

[38] E. Maillet, C. Baker, G.N. Morscher, V.V. Pujar, J.R. LemanskiFeasibility and limitations of damage identification in composite materials using acoustic emission

Compos Part A Appl Sci Manuf, 75 (2015), pp. 77-83, 10.1016/j.compositesa.2015.05.003

[39] M. GrédiacThe use of full-field measurement methods in composite material characterization: interest and limitations

Compos Part A Appl Sci Manuf, 35 (2004), pp. 751-761, 10.1016/j.compositesa.2004.01.019

[40] F. Pierron, B. Green, M.R. WisnomFull-field assessment of the damage process of laminated composite open-hole tensile specimens. Part I: Methodology

Compos Part A Appl Sci Manuf, 38 (2007), pp. 2307-2320, 10.1016/j.compositesa.2007.01.010

[41] F. Pierron, B. Green, M.R. Wisnom, S.R. HallettFull-field assessment of the damage process of laminated composite open-hole tensile specimens. Part II: Experimental results

Compos Part A Appl Sci Manuf, 38 (2007), pp. 2321-2332, 10.1016/j.compositesa.2007.01.019

[42] S.V. Lomov, D.S. Ivanov, I. Verpoest, M. Zako, T. Kurashiki, H. Nakai, et al.Full-field strain measurements for validation of meso-FE analysis of textile composites

Compos Part A Appl Sci Manuf, 39 (2008), pp. 1218-1231, 10.1016/j.compositesa.2007.09.011

[43] P. Feissel, J. Schneider, Z. Aboura, P. VillonUse of diffuse approximation on DIC for early damage detection in 3D carbon/epoxy composites

Compos Sci Technol, 88 (2013), pp. 16-25, 10.1016/j.compscitech.2013.08.027

[44] C. Goidescu, H. Welemane, C. Garnier, M. Fazzini, R. Brault, E. Péronnet, et al.Damage investigation in CFRP composites using full-field measurement techniques: combination of digital image stereo-correlation, infrared thermography and X-ray tomography

Compos Part B Eng, 48 (2013), pp. 95-105, 10.1016/j.compositesb.2012.11.016

[45] G.H. Erçin, P.P. Camanho, J. Xavier, G. Catalanotti, S. Mahdi, P. LindeSize effects on the tensile and compressive failure of notched composite laminates

Compos Struct, 96 (2013), pp. 736-744, 10.1016/j.compstruct.2012.10.004

[46] M.A. Caminero, M. Lopez-Pedrosa, C. Pinna, C. SoutisDamage assessment of composite structures using digital image correlation

Appl Compos Mater, 21 (2014), pp. 91-106, 10.1007/s10443-013-9352-5

[47] C. Furtado, A. Arteiro, G. Catalanotti, J. Xavier, P.P. CamanhoSelective ply-level hybridisation for improved notched response of composite laminates

Compos Struct, 145 (2016), pp. 1-14, 10.1016/j.compstruct.2016.02.050

[48] J.J. Andrew, V. Arumugam, D.J. Bull, H.N. DhakalResidual strength and damage characterization of repaired glass/epoxy composite laminates using A.E. and D.I.C

Compos Struct, 152 (2016), pp. 124-139, 10.1016/j.compstruct.2016.05.005 
[49] M. Mehdikhani, A. Matveeva, M.A. Aravand, B.L. Wardle, S.V. Lomov, L. GorbatikhStrain mapping at the micro-scale in hierarchical polymer composites with aligned carbon nanotube grafted fibers

Compos Sci Technol, 137 (2016), pp. 24-34, 10.1016/j.compscitech.2016.10.021

[50] Schorer N, Sause MGR. Identification of failure mechanisms in CFRP laminates using 3D digital image correlation. In: Proc 20th int conf compos mater ICCM-20, Copenhagen, Denmark 2015:1924.

[51] Suarez E, Sause MGR, Gallego A. Influence of an optical fiber embedded on unidirectional CFRP laminates evaluated with the Acoustic Emission and 3D Digital Image Correlation techniques. Prog Acoust Emiss XVIII, JSNDI IIIAE 2016:441-6.

[52] Mehdikhani M, Standaert A, Steensels E, Gorbatikh L, Lomov SV. Effect of defects on matrix cracking in carbon fiber-reinforced composites investigated by means of digital image correlation at different scales. (SUBMITTED TO ECCM-21); 2018.

[53] F.E. Oz, N. Ersoy, S.V. LomovDo high frequency acoustic emission events always represent fibre failure in CFRP laminates?

Compos Part A Appl Sci Manuf, 103 (2017), 10.1016/j.compositesa.2017.10.013

[54] Hexcel. HexPly ${ }^{\circledR} 8552$ - Product Data Sheet - EU Version 2016:1-6.

[55] ASTM. D3039/D3039M: Standard Test Method for Tensile Properties of Polymer Matrix Composite Materials. Annu B ASTM Stand 2014;14:1-13. doi:10.1520/D3039.

[56] A.E. Scott, M. Mavrogordato, P. Wright, I. Sinclair, S.M. SpearingIn situ fibre fracture measurement in carbon-epoxy laminates using high resolution computed tomography

Compos Sci Technol, 71 (2011), pp. 1471-1477, 10.1016/j.compscitech.2011.06.004

[57] Y. Swolfs, H. Morton, A.E. Scott, L. Gorbatikh, P.A.S. Reed, I. Sinclair, et al.Synchrotron radiation computed tomography for experimental validation of a tensile strength model for unidirectional fibre-reinforced composites

Compos Part A Appl Sci Manuf, 77 (2015), pp. 106-113, 10.1016/j.compositesa.2015.06.018 